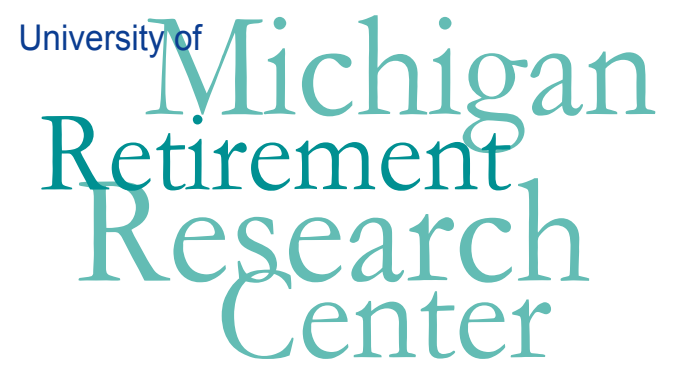

Working Paper WP 2002-024

\title{
The Welfare Implications of Increasing DI Benefit Generosity
}

John Bound, Julie Berry Cullen, Austin Nichols, and Lucie Schmidt

\begin{tabular}{|l|l|l|}
\hline $\mathrm{M}$ & $\mathrm{R}$ \\
\hline $\mathrm{R}$ & $\mathrm{C}$ & \\
\hline
\end{tabular}$\quad$ Project \#: UM 00-12 


\title{
"The Welfare Implications of Increasing Disability Insurance Benefit Generosity"
}

\author{
John Bound \\ University of Michigan and NBER \\ Julie Berry Cullen \\ University of Michigan and NBER \\ Austin Nichols \\ University of Michigan \\ Lucie Schmidt \\ Williams College
}

July 2002

\author{
Michigan Retirement Research Center \\ University of Michigan \\ P.O. Box 1248 \\ Ann Arbor, MI 48104 \\ www.mrrc.isr.umich.edu \\ (734) 615-0422
}

\section{Acknowledgements}

This work was supported by a grant from the Social Security Administration through the Michigan Retirement Research Center (Grant \# 10-P-98358-5). The opinions and conclusions are solely those of the authors and should not be considered as representing the opinions or policy of the Social Security Administration or any agency of the Federal Government.

\section{Regents of the University of Michigan}

David A. Brandon, Ann Arbor; Laurence B. Deitch, Bingham Farms; Daniel D. Horning, Grand Haven; Olivia P. Maynard, Goodrich; Rebecca McGowan, Ann Arbor; Andrea Fischer Newman, Ann Arbor; S. Martin Taylor, Gross Pointe Farms; Katherine E. White, Ann Arbor; Mary Sue Coleman, ex officio 


\title{
The Welfare Implications of Increasing DI Benefit Generosity
}

\author{
John Bound, Julie Berry Cullen, Austin Nichols, Lucie Schmidt
}

\begin{abstract}
The empirical literature on DI has primarily focused on the impact of program parameters on caseload growth or reduced labor force attachment. The focus on the efficiency costs of DI provides a misleading view of the social desirability of the program itself and of the adequacy of benefit levels. In order to provide a more comprehensive view, we develop a framework that allows us to simulate the benefits as well as the costs associated with a marginal increase in benefit generosity using a representative crosssectional sample of the population. Using the 1991 March CPS, we estimate the total cost of providing an additional $\$ 1$ of income to current DI recipients to be $\$ 1.42$. While the load factor due to moral hazard is fairly high, we demonstrate that it is moderate enough that representative workers should be willing to "buy" additional insurance through reduced take-home pay at this price. The reform looks less attractive, however, once the financial benefits and costs are distributed across individuals in the sample. Fist, the average implicit price of an additional dollar of insurance is actually much higher than $\$ 1.42$ for all but the least educated category of workers due to the redistribute nature of the program. We predict that the reform leads to a net welfare loss for these more highly educated groups, regardless of the level of risk aversion. Second, despite an average implicit price of less than $\$ 1$, the expected utility gain also turns negative for high school dropouts under high levels of risk aversion. Second, despite an average implicit price of less than $\$ 1$, the expected utility gain also turns negative for high school dropouts under high levels of risk aversion. This counterintuitive finding arises since the utility calculation weighs low income individuals more heavily as risk aversion increases and individuals with income below the floor provided to current DI recipients help to finance the benefit increase.
\end{abstract}

\section{Authors' Acknowledgements}

The research reported herein was performed pursuant to a grant from the U.S. Social Security Administration (SSA) to the Michigan Retirement Research Center (MRRC). The opinions and conclusions are solely those of the authors and should not be construed as representing the opinions or policy of the SSA or any agency of the Federal Government or of the MRRC. The authors would like to thank Charlie Brown, Michael Chernew, Joel Slemrod, and participants in the University of Michigan Public Finance and RWJ Health Policy seminar series and the NBER Summer Institute for helpful comments and suggestions. Bound and Cullen would like to thank MECA for financial support, and Cullen also gratefully acknowledges support through the Robert Wood Johnson Foundation Scholars Program. 


\section{Introduction}

Disability status is increasingly used as a means for targeting resources in the United States. In 1999, 5.6 million disabled individuals and 1.6 million spouses and dependent children received a total of $\$ 4.2$ billion in Disability Insurance (DI) benefits, representing over one-eighth of the Social Security budget for benefit payments. Given its importance and continuing growth, an evaluation of whether the DI program provides adequate insurance against the income losses associated with the onset of severe limitations is overdue.

The empirical literature on DI has primarily focused on the impact of program parameters on the costs of the program, either in terms of caseload growth or reduced labor force attachment. This focus on the efficiency costs of DI provides a misleading view of the social desirability of the program itself and of the adequacy of payment levels. The effectiveness of the program depends on how the costs relate to the social gains from redistributing toward individuals and states of the world with higher marginal utilities of income. ${ }^{1}$ What is striking is that there has not been any explicit valuation of the benefits associated with providing DI. ${ }^{2}$ In order to provide a more comprehensive view, our analysis accounts for both the benefits and costs associated with a marginal change in benefit generosity. While taking this marginal approach allows us to hold all else equal and greatly facilitates the analysis, it precludes us from global considerations such as optimal program design. Our goal instead is to determine whether, given the degree of moral hazard under the existing DI system, the level of generosity is above or below the optimal level and which factors are important to drawing a conclusion.

How an individual worker fares under this marginal reform depends on the expected change in lifetime utility. This expectation in turn depends on the impact on the path of family income and work effort both in the case where the worker becomes disabled and applies for DI and in the case where the worker never applies, and on the likelihood of each of these outcomes. Our approach is based on the intuition that if the population is in steady state, a representative cross-sectional sample of the population can be thought of as capturing the distribution of potential life-cycle paths for a representative individual or cohort. We can therefore use observed earnings patterns to simulate the impact of increasing DI benefits on family income for current recipients, potential new applicants, and workers in the sample. Combining data from the 1991 March Current Population Survey (CPS) with plausible assumptions about behavioral responses, we calculate the expected financial benefits accruing to and financial costs borne by each individual in the sample as a result of a one percent increase in DI payments.

We then conduct the welfare analysis in two stages. In the first stage, we compare the total costs associated with the reform to the increase in transfers to current recipients. This ratio yields an estimate of the average implicit price of providing an additional dollar of income to current beneficiaries in the presence of moral hazard. This price exceeds one only to the extent that there are behavioral responses to the increase that

\footnotetext{
${ }^{1}$ See Diamond and Sheshinski (1995) for an example of a theoretical framework designed to balance redistribution goals and labor supply disincentives in determining the optimal level of disability payments.

${ }^{2}$ There is a literature documenting the economic disadvantage of the disabled, but this literature has not posed the question in terms of insurance adequacy (e.g., Haveman and Wolfe 1990; Burkhauser, Haveman, and Wolfe 1993).
} 
generate additional tax and transfer costs, including changes in work effort and program participation among current beneficiary and potential applicant families. Using this price, we explore whether representative workers should find purchasing additional insurance through reduced take-home pay financially attractive. ${ }^{3}$ This reveals whether different types of workers are under- or over-insured against career-ending disabilities, given the existing level of generosity and degree of moral hazard in the system. By holding the price constant across worker types, we are able to isolate the insurance value of DI.

In our second approach, we recognize that like other social insurance programs, the value of DI derives from its dual role as a program that both redistributes resources across individuals and insures individuals against adverse events. Thus, for example, for individuals at all levels of education, DI acts as privately provided insurance against the reduction in earnings capacity associated with the onset of disability. At the same time, DI redistributes from those with higher to those with lower levels of education both because replacement rates are higher for lower earners and because the less well educated are substantially more likely to become DI beneficiaries. ${ }^{4}$ In order to determine the lifetime incidence accounting for the underlying distribution of costs and benefits across individuals, we value the change in income for each member of our sample. ${ }^{5}$ The sum of individual valuations describes whether or not individuals gain on average from the payment increase, where this average puts more weight on the low end of the income distribution. The sign of the sum also answers whether a self-interested representative individual would favor a payment increase without knowing her own probability of disability and pattern of life-cycle earnings, but knowing only the social distribution. ${ }^{6}$

To summarize the findings of our baseline model, we estimate the total cost of providing an additional $\$ 1$ of income to current DI recipients to be $\$ 1.50$. While the load factor due to moral hazard is fairly high, we demonstrate that it is moderate enough that representative workers should be willing to "buy" additional insurance at this price. However, the average implicit price of an additional dollar of insurance is actually much higher than $\$ 1.50$ for more highly educated workers due to the redistributive nature of the program. We predict that the reform leads to a net welfare loss for these groups regardless of the level of risk aversion, considering only the role of own income security. More surprisingly, despite an average implicit price of less than $\$ 1$, the expected utility gain also turns negative for high school dropouts under high levels of risk aversion. This counterintuitive finding arises since the utility calculation weights low income states and individuals more heavily as risk aversion increases, and worker-years with current

\footnotetext{
${ }^{3}$ Bird (1996) carries out an analogous analysis for the EITC program, finding that the benefits from reducing income risk compare favorably to the tax costs for many middle income individuals.

${ }^{4}$ Much of the theoretical work in this area relies on static one-period models, with variation across individuals in the degree to which they suffer a disability (modeled as the disutility of work). Productivity differences across individuals are assumed away. In this context, the equity/insurance distinction disappears since everyone is identical.

${ }^{5}$ The fact that we are considering a marginal change in program generosity allows us to ignore changes in utility for individuals who are induced to apply to the program (which would involve valuing changes in leisure) since these individuals are assumed to be indifferent between applying and not applying.

${ }^{6}$ From this perspective of the "veil of ignorance," redistribution and insurance are not separate concepts (Varian 1980).
} 
income below the floor provided to DI recipients help to finance the benefit increase. ${ }^{7}$

These combined analyses suggest that DI payments are higher than optimal. Given the focus on moral hazard costs in the empirical literature, we may have expected that workers would be over-insured under the current system. However, what is surprising is that it is not the degree of moral hazard that leads to this conclusion. Rather, what seems to drive this result is that it only insures against one kind of income risk. Benefit increases are to some extent paid for by able-bodied workers with low incomes and high replacement rates and by disabled workers who do not qualify for DI. This redistribution across various low income states of the world represents a hidden cost of any across the board benefit increase and is relevant to other categorical transfer programs.

It is worth highlighting that the conclusion that workers may be over-insured through DI is derived in the context of a program that currently has relatively high replacement rates. Thus, the results do not at all imply that the optimal level of DI benefits would be low, merely that they would be lower. A modification to our baseline model that incorporates health insurance through its impact on program costs and on utility makes this point even more clear. New public health insurance costs increase the implicit price of additional insurance to $\$ 1.66$, which does not affect our conclusions about willingness to pay for typical workers. However, treating high out-of-pocket health care expenditures as one of the costs associated with disability exaggerates the drop in income at the onset of disability and reduces the effective replacement rate (by approximately 8 percent). This adjustment leads to average utility gains from the marginal increase in benefit generosity that increase with the level of risk aversion. We take this sensitivity to small permutations to imply that the generosity of the current program is not too far from what would be optimal holding the other program parameters constant.

The remainder of the paper proceeds as follows. The next section provides background on the DI program. Section 3 develops the conceptual framework we use to evaluate the welfare impact of increasing DI benefit generosity. Section 4 presents and discusses the results, and Section 5 concludes.

\section{Background}

DI is currently the most important disability program in terms of its scope and the magnitude of expenditures involved. The program provides benefits to disabled workers (and their spouses and children) in amounts related to the disabled worker's former earnings in covered employment. DI benefit payments are calculated in essentially the same way as are retirement benefits. Monthly benefits rise as a function of past earnings, but less than proportionately. Funding is provided through a Social Security payroll tax, a portion of which is allocated to a separate DI trust fund.

To be eligible for DI benefits, a worker must have worked a sufficient number of quarters in Social Security covered employment. ${ }^{8}$ In addition, he or she must not be

\footnotetext{
${ }^{7}$ This result parallels a theoretical result in Diamond and Sheshinski (1995). The optimal level of disability benefits is decreasing in the fraction of non-working individuals who are not on DI, since in their model these individuals have higher marginal utilities of income and are taxed along with workers to finance the benefit increase.

${ }^{8}$ Roughly speaking, an individual has to have worked in covered employment for 5 of the 10 years prior to
} 
gainfully employed and must pass a medical screening. The determination of whether an applicant meets the medical requirements for disability involves a sequential process, under which about half of all applicants are turned down. Generally, the worker must be found incapable of gainful employment, taking into account age, education and work experience. The person must be disabled for a five-month waiting period before he or she can receive benefits. Given continuing restrictions on work, the vast majority of recipients refrain from working at all. After two years on the program, beneficiaries become eligible for Medicare. Successful applicants can expect to continue to receive cash and health benefits for the remainder of their lives. At the age of 65 , beneficiaries are officially transferred from the disability to the retirement program, but their retirement benefits are equivalent to the benefits they received under the disability program.

The fact that DI is targeted to eligible workers distinguishes DI from the second most prominent disability program-Supplemental Security Income (SSI). While DI is essentially an early retirement program, SSI is a means-tested program providing benefits to needy disabled and blind as well as needy aged individuals, regardless of work history. The two programs serve somewhat different populations. The typical DI beneficiary tends to be older and is less likely to be female, a high school graduate, or white than is a typical member of the working aged population. The SSI population is somewhat younger and more female than the DI population and is even less well educated. We focus our attention on the DI program because it functions more directly as an insurance program.

The case for mandatory public insurance for career-ending disabilities is relatively strong. First, given that these types of disabilities represent very low probability events, it is inefficient for individuals to self-insure through own savings. Second, in the absence of government intervention, adverse selection would likely prohibit a market for comprehensive long-term disability insurance from forming. Firms offering private disability insurance would attract those individuals with the highest risk of becoming disabled. At any given price, this form of consumer self-selection may prevent insurance companies from breaking even. The government can overcome problems of adverse selection by requiring participation, so that low-risk individuals are forced to pool with high-risk individuals. While supplementary private insurance packages are currently available to some classes of workers, this market presumably owes its existence partly to the primary insurance offered by DI. In fact, the early private insurance market established before the public system was introduced collapsed during the Great Depression and was eventually resurrected with more limited coverage (U.S. Senate 1955).

Though public insurance can solve adverse selection problems, DI is not necessarily any more immune to moral hazard than private programs. The striking historical correlation between trends in DI participation and reduced labor supply among elderly males has led to a large literature measuring the disincentive effects of DI. Though the empirical evidence suggests that the typical DI beneficiary would be out of the labor force regardless, the same is not true of individuals on the margin who are induced to apply by increases in the availability and generosity of benefits (Bound and Waidmann 1992, 2002; Autor and Duggan, forthcoming). Though DI is associated with large

the point in time the worker becomes disabled. 
behavioral distortions, there is little in the literature that would permit one to say whether these sizeable effects outweigh or are outweighed by the benefits of the program. ${ }^{9}$

\section{Conceptual Framework}

\subsection{Determining whether typical workers gain}

The goal of the first phase of our analysis is to establish whether representative workers should be willing to trade reduced take-home pay for increased DI benefits, given the degree of actuarial unfairness associated with the program. The program is actuarially unfair on average because of moral hazard. That is, since higher benefits lead to behavioral responses that increase the cost beyond the amount that is actually transferred to current recipients, it will cost more than $\$ 1$ to increase the income of the disabled by $\$ 1$. However, workers may still want to purchase additional insurance at this price if the marginal utility of income is high enough in the disabled states of the world.

The value of additional insurance to workers depends on how important own earnings are to family income and the rate at which DI replaces lost earnings, as well as the level of risk aversion.

The experiment that we consider is a one percent increase in DI payments. This experiment is clearly artificial since we leave retirement benefits unchanged despite how closely the two programs are linked. ${ }^{10}$ It is not meant to capture a realistic policy but provides a concrete way for us to evaluate how individuals value DI at the margin. Given the marginal policy change, we first calculate the static costs due to the increase in transfers to DI beneficiaries holding behavior constant. Then, we add the dynamic tax and transfer costs associated with the behavioral responses of current beneficiaries as well as other individuals to the payment increase. From this point forward, we refer to the static costs as "direct" costs and the dynamic costs as "indirect costs." The average implicit price of providing an additional dollar to current DI recipients is simply the ratio of total to direct costs.

While calculating these costs may seem straightforward, consider the difficulties that arise when determining even the direct increase in DI payments to current beneficiaries. Individuals who enter the program when they are 35 continue to receive benefits from then on. We would, therefore, need to project benefits forward to determine the full cost. $^{11}$ We greatly simplify our task by making the following steady state assumption. As long as the overall population and the fraction receiving DI are not growing, the age distributions of both the overall population and of DI recipients are not changing, and there is no productivity growth, we can measure the costs from a random sample of the population. Each individual in the cross-section can be conceptualized as depicting the

\footnotetext{
${ }^{9}$ A notable exception is Gruber's (1996) analysis of a discrete change in benefit generosity in Canada that concludes with a back-of-the-envelope calculation of the net utility benefits to current beneficiaries, marginal applicants, and workers.

${ }^{10}$ Note that we do account for increases in payments to elderly that were DI recipients prior to aging into the retirement program.

${ }^{11}$ Longitudinal Social Security records that track individual earnings and benefits over time might appear to solve the informational problem. However, these records do not provide information on family income amounts and sources over time that is integral to our calculations.
} 
circumstances at one age within a possible life cycle path for an individual. Then, payments to 45 -year olds on the program today can be thought of as picking up the payments to 35-year olds ten years hence. While this steady state assumption may not be particularly realistic in the context of the current age structure in the United States, as we discuss later, sensitivity tests suggest that maintaining this assumption does not substantially affect our results.

To measure the direct costs, we identify current recipients in our sample and increase family benefits by one percent. Note that beneficiaries are found among the elderly as well as the working-aged population since our framework views an elderly person as the aged version of a working aged individual. In order to identify the full impact of the reform, we need to identify which elderly individuals would have been DI beneficiaries in their working years. Appendix A describes how we identify beneficiaries and how we determine the baseline level of family DI payments.

The resulting change in public transfers to these families is moderated by mechanical interactions with other programs. We use payment algorithms to reduce cash SSI and inkind Food Stamp amounts received. ${ }^{12}$ Finally, the resulting net increase in income will lead to higher income taxes paid by current beneficiaries. We use TAXSIM to estimate the change in federal and state income taxes paid. ${ }^{13}$ The total direct costs of the reform are, therefore, the increase in DI benefits paid less any reduction in other transfers and any increases in taxes paid, summed across families. This sum represents the net additional public outlay to families with current beneficiaries, as well as the net increase in income for these families.

We use this same steady state framework to calculate two sets of indirect costs. First, we allow current beneficiaries and their families to respond to the lump sum increase in income. Own labor supply has little room to respond given the restriction on gainful work imposed by DI, although family labor supply responses could potentially be sizeable (Cullen and Gruber 2000). Any reduction in labor supply represents a program cost since it will result in reduced income and payroll taxes paid by the family. Relying on the broad thrust of the literature on the long run income elasticity of labor supply (see Killingsworth 1983), we assume that husbands of current beneficiaries continue to earn the same as before, but apply an income elasticity of negative one to wives of current beneficiaries. After calculating the reduction in spousal earnings, we estimate the associated tax cost.

The second set of indirect costs that we consider has been emphasized in the prior literature on DI - those associated with new applications. The magnitude of these costs will depend on the number of new DI applicants, as well as how many of these new applicants pass the medical screening. Successful new applicants will receive DI payments. ${ }^{14}$ Further, changes in the income and labor supply of successful and

\footnotetext{
${ }^{12}$ For those low-income recipients who are currently receiving SSI benefits, the net change in transfers will actually be zero since SSI benefits are reduced one-for-one with DI benefits.

${ }^{13}$ TAXSIM is the National Bureau of Economic Research's FORTRAN program for calculating liabilities under the U.S. federal and state income tax laws from individual data. We use version 4.0 available at URL (http://www.nber.org/taxsim/). For more information about TAXSIM, see Feenberg and Coutts (1993).

${ }^{14}$ Since we are analyzing a marginal change and these individuals are assumed to be just indifferent between applying or not, we can ignore the value of these payments and account for them solely on the cost side. That is, they affect only the numerator and not the denominator of the implicit price.
} 
unsuccessful applicants and their families may lead to increased participation in other transfer programs as well as lower tax payments. The costs of the policy change include not only the DI benefit payments to new successful applicants, but also increased public transfers and reduced tax revenue associated with successful and unsuccessful applications.

We rely on evidence from prior literature to predict how many new applicants and beneficiaries will result from the policy reform. Although estimates of the elasticity of applications with respect to benefit generosity vary considerably (Bound and Burkhauser 1999), plausible bounds exist. The estimates we find the most credible are based on time series evidence from the 1960s and 1970s, a period of time when replacement ratios rose appreciably (Halpern 1979; Lando, Coate and Kraus 1979). These estimates suggest elasticities in the neighborhood of $0.5 .^{15}$

We need to link the application elasticity to the size of the current pool of recipients. Historically, roughly half of those who apply for DI are awarded benefits (Bound and Burkhauser 1999), which would imply a ratio of ever-applicants to beneficiaries of two. The ratio will be greater than this estimate to the extent that mortality is higher among successful than unsuccessful applicants, and will be smaller to the extent that many individuals apply several times. Using the matched SIPP-SSA data described in Appendix B, we are able to estimate the ratio directly for individuals included in the SIPP panels whose applications were acted upon between 1977 and 1997 and find that the two effects largely cancel. Therefore, we assume that the steady state number of applicants is approximately twice as large as the recipiency base. This implies that the elasticity of beneficiaries with respect to benefits is the same as the application elasticity. ${ }^{16}$

Thus, our baseline assumption is that a $1 \%$ increase in benefits leads to a $0.5 \%$ increase in applications, and the same percentage increase in beneficiaries. Marginal applicants are assumed to be observably similar to current DI beneficiaries. We describe in Appendix A how we identify new unsuccessful and successful applicants in our sample and assign DI family payments to them.

We conduct detailed analyses with matched SIPP and SSA data to guide the assumptions that we make about the behavioral responses of marginal applicants and their families. Our methodology allows us to trace out the impact of both successful and unsuccessful applications. The most important behavioral responses are changes in own labor supply, which then lead to additional costs associated with increases in transfer payments and decreases in tax payments. Details on how we determine which behavioral responses are relevant and estimate the associated costs are provided in Appendix B.

Though we account for the most obvious behavioral responses, we ignore several classes - some of which we expect to have a negligible impact on our calculation and others that are potentially important but about which we can do little. We ignore the deadweight burden associated with raising taxes to pay for the increased DI payments. Empirical evidence (Gruber 1994; Anderson and Meyer 1995) suggests that payroll taxes

\footnotetext{
${ }^{15}$ Cross-sectional estimates vary considerably, from a low of 0.2 to a high of 1.3 . Kreider (1999), with the most credible econometric model, estimates an elasticity of 0.8. See Bound and Burkauser (1999) for a review of this literature.

${ }^{16}$ It seems likely that those induced to apply by an increase in benefits would tend to be less severely impaired than the typical applicant. In this case, they would be less likely to pass the screening. Since unsuccessful applicants cost less in terms of taxes and transfers than do successful applicants, our assumption should lead to an overestimate of the costs of a payment increase.
} 
that support programs that are restricted to workers are essentially benefit taxes, so that the deadweight burden of the tax increase will be negligible. However, as we demonstrate, DI is far from a pure benefit tax since it involves substantial redistribution across worker types. Easy solutions to account for deadweight loss, such as scaling the tax costs upward using factors estimated in the literature, will not work in this case, since some individuals receive subsidies and others are taxed. Ignoring this cost is equivalent to assuming the net burden is zero.

We also ignore a variety of other responses to changes in DI benefit generosity, such as changes in savings, marriage rates, or participation in private disability insurance programs. We suspect that none of these effects is likely to be large. The occurrence of a long-term disability during a person's working years is a relatively rare event, but is likely to represent a reasonably permanent state. Though both savings and marriage significantly mitigate the costs of becoming disabled, neither form of self-insurance against this eventuality is very effective. For this reason, neither is likely to be heavily used or to respond to changes in benefit levels. ${ }^{17}$ Though apparently a more viable alternative, applicants for DI are not typically covered by any type of private disability program, leaving little room for crowd-out along this margin. ${ }^{18}$

Using our estimates of the costs that we are able to measure, we then calculate the ratio of total to direct costs. In order to determine whether a representative individual would be willing to purchase additional insurance at the implied price, we need to determine the relative value of income to an individual across able-bodied and disabled states of the world. We assume a utility function that exhibits constant relative risk aversion, and is separable in consumption and leisure:

$$
U(C, H)=v(C)-f(H)=\frac{C^{1-\theta}}{1-\theta}-f(H),
$$

where $C$ is consumption, $H$ represents hours worked, and $\theta$ is the coefficient of relative risk aversion. ${ }^{19}$ Given this utility function, the marginal utility of income is $C^{-\theta}$. The relative value of $\$ 1$ across the two states of the world can be expressed as $\left(\frac{C_{d}}{C_{n d}}\right)^{-\theta}$, where $C_{d}$ represents consumption when disabled and $C_{n d}$ represents consumption when able-bodied. We rely on matched SIPP and earnings records (SER) data to estimate the relative consumption levels for DI-insured individuals. Then, we compare willingness to pay calculated at varying levels of risk aversion to the average implicit price.

\subsection{Determining whether workers benefit on average}

Given our estimates of the direct and indirect costs, the distribution of these costs across workers determines how the average worker fares. While DI transfers resources

\footnotetext{
${ }^{17}$ Moreover, median savings among those who apply for DI benefits in the matched SIPP-SSA sample are only $\$ 600$.

${ }^{18}$ Only $8.5 \%$ of DI recipients in the March 1991 CPS report receiving private disability insurance. Those who receive private benefits tend to have more years of education than those who do not (12.5 vs. 10.3).

${ }^{19}$ What is important is not the specific functional form, but the implication that individuals value $\$ 1$ more when they are poorer than when they are richer, and that these relative values do not vary with hours of work. We use this as a heuristic for determining the marginal value of income across states.
} 
from younger to older individuals and from able-bodied to disabled individuals in the cross-section, from our steady-state perspective DI transfers resources from earlier to later years and across different states of the world. If the cross-sectional distribution captures the full distribution of potential life-cycle paths, then the net benefits to the random sample measure the average life-cycle incidence.

Our approach is to first simulate the change in utility following the reform for each individual in our sample, and then to aggregate across all individuals. To clarify our approach, it is helpful to decompose the sum of utilities in the following way:

$$
\begin{aligned}
& W=\sum_{i j t} v\left(C_{i j t}\right)-f\left(H_{i j t}\right)=\sum_{i} \sum_{j t} v\left(C_{i j t}\right)-f\left(H_{i j t}\right) \\
& d W=\sum_{i} \sum_{j t} \frac{d v}{d C_{i j t}} d C_{i j t}-\frac{d f}{d H_{i j t}} d H_{i j t}
\end{aligned}
$$

where $i$ indicates individual, $j$ indicates possible realizations (e.g. disabled or not), and $t$ indicates the time period or age. Each member of our sample can be conceptualized as representing a point in time on one possible life path for an individual. Imagine all of the observations representing a given individual's possibilities, and imagine that individual at some base period early in her life. Also, focus on the financial component of utility. As we justify more fully below, this is reasonable for our analysis since we do not have to explicitly value changes in leisure for the marginal applicants who are assumed to neither gain nor lose from the reform and since the changes in work effort for families of beneficiaries operate through income effects. ${ }^{20}$ Our calculation of $\frac{d v}{d C_{i j t}} d C_{i j t}$ for these observations can be thought of as that person's report of how she values the change in consumption in time period $t$ and state $j$ caused by the reform. The sign of the sum across $j$ and $t$ describes whether she directly benefits from the reform or not. ${ }^{21}$ Subsequently aggregating across different persons weights their net valuations by the relative marginal values of income at the base period.

While conceptually we can separate individuals and life paths, it is impossible to do so in our cross-section. The role of the risk aversion parameter is complicated in this setting. From the perspective of a given individual, the utility gain from reducing the potential income loss from the onset of disability depends on the level of risk aversion in the traditional manner. A higher level of risk aversion increases the weight on low income periods, making insurance more desirable. But, in the welfare calculation, a higher level of risk aversion also increases the weight that low income individuals receive. The social net benefit of the reform will vary with the coefficient of relative risk aversion through both of these channels, so that inequality-aversion and risk-aversion effects are entangled.

We derive the individual-, realization-, and period-specific components of equation (2) by simulating the point in time change in utility for each person in our CPS sample. We begin by distributing the costs of the increase in DI benefit generosity according to 1990

\footnotetext{
${ }^{20}$ Note that we ignore any deadweight burden associated with changes in tax payments required to finance the reform that would involve changes in work effort for worker families.

${ }^{21}$ While this approach implicitly discounts by mortality, it assumes individuals do not otherwise discount the future. We make this assumption based on survey evidence (Barsky et al. 1997) that suggests time discounting is negligible. We did, however, check the robustness of our results. In qualitative terms, our results hold for any reasonable discount values.
} 
funding patterns. That is, increases in DI benefit payments and decreases in payroll taxes paid are shared across workers in proportion to earnings below the Social Security maximum. Net tax costs due to lost income tax revenue and increases in other transfers are distributed according to workers' shares of federal and state income taxes paid. ${ }^{22} \mathrm{We}$ can then simulate the impact of the reform on family income for current beneficiaries, potential new applicants, and workers. In this case, how workers are affected by increasing DI generosity depends on both the progressivity of DI replacement rates and of the tax code. ${ }^{23}$ The degree to which the increased insurance is actuarially unfair is folded into the analysis since the predicted shifts in family income absorb the tax increases due to direct and indirect financial costs.

The next step is to translate the changes in income and leisure into changes in utility. Assuming that utility takes the form described above, we are able to focus exclusively on the financial component. The only changes in leisure considered in our analysis are among families of current beneficiaries and marginal applicants. For the families of current beneficiaries, the increase in transfers (net their share of costs) is valued ignoring any changes in spousal earnings and leisure. Though these families choose to "spend" some of the increase in income on increased leisure, the marginal utility gain can be captured through the income effect. While the direct benefits accrue to those already on DI through the increase in income, indirect benefits accrue to the individuals induced to apply for DI benefits. However, since these individuals are at the margin, revealed preference suggests that they will gain relatively little from the increase. Thus, we assume that the change in utility for marginal applicants is zero. ${ }^{24}$ Other families experience only a change in income proportional to their share of costs.

Finally, we need to specify how changes in family income are converted to changes in individual consumption. One alternative is to simply proxy for consumption using per capita family income. However, there is evidence that families are capable of buffering themselves against short-term fluctuations in income. Therefore, we also use an alternative proxy to account explicitly for divergence between income and consumption due to saving. We use data from the Consumer Expenditure Survey (CEX) to calculate the relationship between concurrent family income and consumption, and then smooth family income accordingly. ${ }^{25}$ In addition, for both smoothed and unsmoothed family income, we calculate both a strict per capita measure and a per capita equivalency. In the

\footnotetext{
${ }^{22}$ AFDC costs are divided between the state and federal tax bases according to the 1990 AFDC cost sharing formulas.

${ }^{23}$ While the above method of distributing costs is the most immediately policy-relevant approach, a second method would instead distribute the net costs across workers in proportion to expected net benefits. Expected net benefits would be based on a worker's age-adjusted position in the earnings distribution and would require information on the pre-application position of DI applicants. This would have the advantage of more effectively isolating the insurance value of increased benefit generosity because the degree to which the policy change is actuarially unfair (e.g. expected financial payments exceed expected benefit receipts) reflects only the relative magnitude of the costs arising from moral hazard.

${ }^{24}$ Note that marginal applicants' indifference is from the point of the health shock onward (as in Diamond and Mirrlees 1978). To the extent that the aggregate demand curve for DI benefits is not smooth and continuous in the level of generosity, then we ignore a non-zero gain to this group and thus underestimate the benefits associated with increasing DI payment generosity.

${ }^{25}$ The methodology is described in detail in Appendix C. Note that our approach does not allow for perfect smoothing of consumption across high and low income periods, so that the marginal utility of income is falling with income for individuals.
} 
equivalency measure, family income is divided by a factor that accounts for both differences in consumption between children and adults and economies of scale. ${ }^{26}$

The estimated changes in consumption are then fed through the utility function to calculate $d U_{i j t}$ for each CPS sample member. The sum of the net gains in utility determines the social value of increasing DI payments. The same calculation for workers with given characteristics determines the value of the policy change to subsets of individuals. We present results at both low and high levels of risk aversion in order to test the sensitivity of our findings.

\subsection{The Role of Health Insurance}

Up until this point we have ignored the role that medical insurance plays in both welfare analyses. For the first analysis, if potential applicants become newly eligible for public health insurance programs, the total costs of the reform may increase. Though determining this net fiscal externality is very difficult, we choose an approach that provides a clear upper bound on the new public health insurance costs associated with marginal applicants. We assume that all individuals that were not receiving public insurance prior to applying but then shift to public insurance generate net new health care costs. Details are provided in Appendix B. The new Medicare costs are distributed across families according to their share of earnings subject to the Medicare tax. The new Medicaid costs are divided between federal and state tax bases according to the costsharing formulas, and are then distributed across the population according to shares of federal and state income taxes paid.

The role that health insurance plays in the second welfare analysis is much more complicated. Valuing medical insurance for marginal applicants, albeit implicitly since we continue to assume they are just indifferent between applying and not applying, requires valuing medical insurance for the working population as well in order to determine baseline utility. The relevant value is not the dollar value of benefits but the insurance value. Imagine that insurance status has little effect on what kind of medical procedures one has, but affects only the out-of-pocket costs. Then, the cost of being uninsured is the possibility of having to pay large medical bills and can be modeled as a loss of income. We estimate heterogeneity in the exposure to distributions of out-ofpocket expenditures for families by age of the head and type of insurance coverage using empirical distributions in the CEX (see Appendix D). We then randomly reduce after-tax income by a draw from the appropriate distribution before proceeding.

\section{Results and Discussion}

The random sample of the population that serves as the basis for our analysis comes from the March 1991 Current Population Survey (with income data for calendar year 1990). Our sample consists of 158,318 individuals residing in 73,638 tax-filing units. ${ }^{27}$

\footnotetext{
${ }^{26}$ We use the adjustment factor suggested by Citro and Michael (1995): $\left(\mathrm{N}_{\mathrm{a}}+.8 * \mathrm{~N}_{\mathrm{c}}\right){ }^{0.7}$, where $\mathrm{N}_{\mathrm{a}}$ is the number of adults and $\mathrm{N}_{\mathrm{c}}$ is the number of children.

${ }^{27}$ Our definition of tax-filing units essentially matches the CPS definitions of subfamilies, except that adult unmarried children residing with their parents are considered to be their own tax-filing units.
} 
We take both the size of the disability population and the implementation of the program (e.g. screening stringency) as given when evaluating the desirability of increasing benefit generosity. Since 1990 predates the recent surge in program growth, ${ }^{28}$ we tested to ensure that the results are robust to inflating the DI population to current levels. ${ }^{29}$ Another issue immediately arises with our assumption that the population is in steady state. The hump-shaped age distribution we observe in the CPS is not consistent with a feasible steady state. That is, the fraction of the population that falls within each age category has to be monotonically declining, or at least non-increasing. The results are robust to re-weighting the sample assuming constant fertility and mortality weights to approximate a feasible steady state distribution. ${ }^{30}$

\subsection{Direct and Indirect Costs of the Reform}

We have divided the costs associated with the increase in DI payment generosity into two main categories. Direct (static) costs result from the transfer of additional income to current beneficiaries, and involve no behavioral response. Indirect (dynamic) tax and transfer costs are generated by the behavioral responses of individuals to the regime change. Our estimates of the costs by category are shown in Table 1.

The first components of direct costs are calculated by scaling family payments for current working aged and elderly DI beneficiaries to reflect the $1 \%$ increase in generosity. For worker beneficiaries, this generates direct costs of $\$ 191.1$ million. For elderly beneficiaries, we have taken into account both the probability the individual was a DI worker beneficiary and whether the individual generates benefits based on own work history. $^{31}$ The expected direct cost of increased payments to elderly beneficiaries is $\$ 129.6$ million. These increases in DI payments are mechanically offset by the interaction of the DI program with other transfer programs, leading to costs savings of \$29.8 million. Finally, these families owe additional federal and state taxes, leading to savings of $\$ 4.6$ million in federal and state income taxes. The sum of these components is the net new transfer to current DI recipients assuming no behavioral response, and totals \$286.3 million.

We account for two main types of indirect costs generated by the behavioral responses to the regime change. First, we account for spousal labor supply responses to the increase in transfers to current beneficiaries. These responses reduce the amount of taxes owed by families of beneficiaries, leading to a loss of $\$ 2.2$ million in federal, state, and payroll tax collections.

The second set of indirect costs is generated by the response of those individuals induced to apply by the policy change. The most important of these are due to the new DI payments to successful applicants. The total simulated cost of these new DI payments is $\$ 89.7$ million, which is about one-fourth as large as the direct cost of increased

\footnotetext{
${ }^{28}$ See Stapleton et al (1998) for a discussion of the various factors behind this recent growth.

${ }^{29}$ As expected, inflating the size of the DI population to current levels increases the implicit price of insurance, but only from $\$ 1.50$ to $\$ 1.51$. It has no qualitative impact on the welfare implications of the policy reform.

${ }^{30}$ The implicit price of an additional dollar of insurance falls slightly, from $\$ 1.50$ to $\$ 1.42$, and there is no qualitative effect on the welfare implications.

${ }^{31}$ If the individual currently receives a Social Security benefit amount determined by a retired or deceased spouse's benefit eligibility, the reform will have no impact on SSDI payments or on family income.
} 
payments to existing beneficiaries. ${ }^{32}$

The remaining indirect costs associated with marginal applications are due to reductions in own labor supply and resulting changes in public transfers and taxes. To calculate these, we take into account the likelihood of successful and unsuccessful applications, and the likelihood that rejected applicants return to work. The resulting income and payroll tax costs total $\$ 50.9$ million. We predict savings of $\$ 0.5$ million on AFDC payments, since few marginal applicants receive AFDC in the base case, few become eligible as unsuccessful applicants, and most successful applicants become ineligible. Costs associated with the Food Stamp Program are \$0.4 million, driven partially by less restrictive income limits for disabled individuals. Finally, SSI benefits to new successful applicants add $\$ 0.3$ million to the costs of the policy change. The costs generated by behavioral responses to the regime change total $\$ 143.0$ million.

The relative magnitudes of the various costs provide some insights into which of the maintained assumptions are likely to qualitatively affect our results. Altering our assumptions about the spousal labor supply response for current beneficiaries would clearly have very little effect. While we are fairly confident that we have accurately captured the impact of application to DI on behavior, we are less certain about how accurately we have captured the number of new applications that would result from a marginal increase in generosity. A larger or smaller receipt elasticity would scale the indirect costs approximately proportionately, which highlights the key role that this form of moral hazard plays in determining whether payments are currently too high or too low. ${ }^{33}$

\subsection{Representative Workers' Willingness-to-Pay}

Our calculations of total direct and indirect costs yield an estimate of the average degree of actuarial unfairness associated with the "purchase" of an additional dollar of DI benefits through reduced income for non-recipients. The ratio of total costs to the direct costs, which capture the net transfer to current DI recipients, is equal to 1.50. For every $\$ 1$ of income transferred to current recipients, an additional 50 cents are incurred in indirect costs.

We use our estimate of the average implicit price to calculate whether representative individuals should be willing to pay for increased benefits. These calculations are presented in Table 2. The medians shown are calculated from the subset of the 1990-93 SIPP sample that is aged 45-61 and is eligible for DI. Assume that when a person becomes disabled, own earnings are lost and they are replaced to some extent by DI benefits. Then, the value of additional insurance will be greater the more important own earnings are to family income and the lower is the share of earnings replaced by DI. The first two columns in Table 2 present the share of own earnings in household income and the ratio of projected family DI payments to own earnings by gender and educational

\footnotetext{
${ }^{32}$ As a plausibility test, we compare the indirect DI payment cost for working aged individuals to an alternative crude calculation. Indirect payments should be approximately equal to total payments to current working aged beneficiaries multiplied by 0.005 (the $1 \%$ benefit increase times the application elasticity). The ratio between the amount resulting from our more involved calculation and this amount is 0.94 .

${ }^{33}$ For example, with an application elasticity of 0.8 (Kreider 1999), the indirect and total costs would be roughly $60 \%$ and $20 \%$ higher, respectively, than those we estimate.
} 
attainment. While there are no clear patterns in own earnings share by education, the progressivity of the payment schedule generates a sharp decline with education in the share of own earnings replaced. It is not surprising, then, that the pre- and post-tax replacement rates for family income shown in the next two columns also decline sharply with education.

As discussed in the prior section, given a separable constant relative risk aversion utility function, the relative value of a dollar in the two states can be expressed by the ratio of income in the two states raised to the power of the negative relative risk aversion parameter. This measure of willingness to pay, based on after-tax family income replacement rates, is reported in columns 5-7 for levels of risk aversion equal to one, two, and four respectively. Because of the higher drop in family income between able-bodied and disabled states, willingness to pay is higher for more highly educated groups. Similarly, willingness to pay is higher for men than women, since the share of women's earnings in family income is lower. While DI-eligible men of all education levels would find purchasing additional insurance at a price of $\$ 1.50$ attractive at levels of risk aversion at or above two, the same holds for all eligible females only at levels above two. Though based on a somewhat older population, recent survey evidence finds mean levels of risk aversion slightly above four (Barsky et al. 1997). At this level, all of our representative individuals would be willing to purchase an additional $\$ 1$ of insurance at a price of $\$ 1.50$. This implies that if the reform could be financed so that individuals were to absorb the costs in proportion to their share of expected payments, an increase in DI benefits would move the level closer to the optimal level. Given replacement rates of between 0.7 and 0.8 for the typical worker, this result emphasizes the substantial value individuals put on the insurance DI provides.

Now, we consider the fact that different individuals must pay different prices for increased insurance given the redistribution within the program. Rather than relating overall direct costs to total costs, we consider how these costs are distributed across individuals with higher and lower levels of education. Table 3 shows the average share of costs borne by families according to years of education of the family head. The majority of costs are distributed in proportion to earnings under the payroll tax cap. The least-educated families pay $\$ 1.52$ in total costs (annually) and the most educated pay $\$ 5.88$ on average through reduced take-home pay. The resulting distribution of costs is mildly progressive, as shown in the fourth column in Table 3.

Comparing these average costs to the expected benefits by level of education provides a crude sense of variation in actuarial unfairness. The expected increase in DI benefit receipts is much higher for less educated families due to a likelihood of receipt that is nearly eight times as great as for the most educated families. The benefit increase provides an additional dollar to these families at a price of only 32 cents. All other families pay more than one dollar, with the college-educated paying over seven dollars. Clearly, DI is not a particularly "good deal" for the typical individual with more than a high school education.

\subsection{Life-Cycle Incidence for Average Workers}

In this section, we convert the changes in family income to changes in individual

utility to evaluate the net welfare impact of the increase in DI benefits. Before converting 
the dollar values to utils, we first summarize the changes in family income in Table 4. The first three columns of Table 4 present average pre-reform income for individuals classified by three point-in-time family types: families with no DI beneficiary, families with a working aged DI beneficiary, and families with an elderly DI beneficiary. The six rows are based on three concepts of income: family income, per capita income, and per capita income adjusted for economies of scale and for the number of adults and children in the family. Each of these three measures is presented unsmoothed and smoothed to account for the relationship between concurrent family income and consumption.

Baseline unadjusted family after-tax income is larger for individuals in families with no DI beneficiary $(\$ 28,455)$ than for those in families with either a worker beneficiary $(\$ 22,302)$ or an elderly beneficiary $(\$ 21,655)$. However, the gap narrows when family income is smoothed. The difference between families with and without beneficiaries becomes even smaller when income is expressed in per capita terms. In fact, the average income for individuals in families with an elderly DI beneficiary is larger than that for families with no limited individuals for three of the four per capita measures.

The next three columns of Table 4 show the post-reform change in the various measures of income. As expected, individuals in families with no beneficiary face income losses while individuals in families with either a working aged or elderly beneficiary experience increases in income. The initial level of income and the change in income determine the measured impact on the financial component of utility for each individual.

Table 5 shows changes in social welfare for different levels of risk aversion and different measures of individual income. The first column indicates the value of the coefficient of relative risk aversion $(\theta)$. The next four columns show the average change in utility for individuals in the three different types of families and in all families. For ease of interpretation, the changes in utility are expressed in monetary terms. Specifically, the values shown are the average change in utility divided by the average pre-reform marginal value of $\$ 1$ for individuals within each sample.

Recall that social welfare is calculated using a utility function that exhibits constant relative risk aversion of the form shown in equation (1). If individuals are risk neutral $(\theta$ equal to zero), utility is simply measured by individual income. Since our reform throws away 50 cents for every dollar transferred to beneficiaries, there must be a net loss in welfare under risk neutrality. What becomes clear from the results presented in Table 5 is that the policy reform leads to a net welfare loss for larger values of $\theta$ as well.

The pattern of net welfare impacts (as normalized by the relevant average pre-reform utility) across levels of risk aversion in Table 5 is surprising. The net welfare loss at first shrinks and then becomes larger as the level of risk aversion increases. It appears that a representative individual from behind the "veil of ignorance" would be less willing to pay for higher disability benefits when very risk averse. This is counterintuitive, since at higher levels of risk aversion the insurance motive should become more important and we would expect the policy reform to become more attractive.

For the welfare of a given individual to fall as the level of benefits rises, the individual must not want to transfer resources from able-bodied to disabled (and on DI) states of the world. This will be true so long as replacement rates are sufficiently high for the individual to be unwilling to pay for the increase. Since DI payments are a function of average earnings, they will tend to be high (and may even be above 1) during periods 
when earnings are low - either early in a person's working life or during prolonged negative earnings shocks that are not associated with disability. Given the progressivity of the benefit formula, replacement rates will also be high for low income workers. What happens in our calculations as the level of risk aversion is raised is that the marginal value of a dollar in low income states rises. Within individuals, more weight is put on low income periods of time. Across individuals, more weight is put on the low income households with generous replacement rates. Together these two factors lead to the pattern of results we see.

Table 6 shows how the net welfare impact varies for more and less well-educated individuals at different levels of risk aversion. ${ }^{34}$ The entries are comparable to the numbers in the final panel and last column of Table 5. They represent the average change in utility, normalized by average baseline utility, associated with the reform. These results again stress the redistributive component of the DI program. For all individuals with a high school education or greater, at all levels of risk aversion, the policy change causes a loss in net welfare. For individuals with less than a high school diploma, there is a net welfare gain - for all but the highest level of risk aversion. Again, while the price is favorable on average for individuals with low education due to moderate moral hazard costs and redistribution from the more highly educated, the gain turns negative at high levels of risk aversion due to redistribution from low to modest income states of the world for a sufficient number of individuals within the low education sample.

The results shown in Table 7 isolate the role of the redistribution built into the financing of the DI program. We set the indirect costs to zero, so that the only costs associated with the reform are the direct costs. This implies no behavioral responses to the policy change, and therefore an average implicit price of additional insurance of one. Under risk neutrality, those with a high school degree or less have expected increases in income while those with some college or more have expected decreases. The average net benefit is negative at all levels of risk aversion for the more highly educated and, as above, turns negative at higher levels of risk aversion for the less educated groups. The general similarity of the results between Tables 6 and 7 highlights the fact that the reason we are finding payment increases do not increase welfare has more to do with the fact that in a sufficient number of cases such increases involve transfers from lower income states of the world rather than any moral hazard considerations.

\subsection{Incorporating Health Insurance}

We first incorporate health insurance on the cost side. Marginal applicants that shift to public health insurance coverage post-application are estimated to generate additional indirect costs of $\$ 45.3$ million. This raises the average implicit price of an additional dollar of insurance by $10.7 \%$, from $\$ 1.50$ to $\$ 1.66$. This increase is not great enough to affect many of our conclusions based on representative agents.

Despite the moderate change in total costs that must be distributed, incorporating health insurance could have a potentially important effect on the average welfare

\footnotetext{
${ }^{34}$ Tables 6, 7, and 8 present results for per capita family income adjusted for economies of scale and the number of adults and children as described above. Results for pure per capita income do not differ qualitatively.
} 
analysis. Recall that we incorporate the value of medical insurance by modifying aftertax income by a draw from distributions of out-of-pocket medical costs specific to insurance status. As the figures in Appendix D show, health insurance status in the crosssection is largely a proxy for heterogeneity in health. Out-of-pocket expenditures are consistently highest for the group covered by Medicare, which for younger households consists of disabled individuals. Expenditures are actually lowest for the uninsured. Therefore, our adjustment will tend to make DI families appear relatively worse off in the baseline and would be expected to make the reform more attractive.

Table 8 shows the average welfare impact by education status when the additional health insurance costs are distributed across the population and baseline utility is adjusted to account for insurance. For all but the highest education group, the average change in utility due to the policy reform steadily rises with the level of risk aversion. Once it is recognized that disabled individuals have lower disposable income than non-disabled individuals with the same level of family income due to their higher medical expenses, the consumption floor provided by DI is low enough that the perverse effect from taxing low-income disadvantaged workers to finance the transfers no longer shows up. Though those with a high school degree or more continue to be made worse off on average by an increase in payment generosity, the net impact for all individuals combined is positive at moderate levels of risk aversion.

Under this modification to our approach, the basic conclusion for whether the program is too generous or not is reversed. We can use a back-of-the-envelope calculation to determine by how much incorporating medical insurance has changed the effective replacement rate for after-tax family income. According to our CEX estimates, average out-of-pocket medical expenses are $14.2 \%$ of income for families with DI beneficiaries, compared to $6.2 \%$ for other families. If the 8 percentage point difference were simply attributable to the onset of disability (likely an upper bound), this would imply that aftertax replacement rates fall by nearly $8 \%$. The fact that these relatively small changes in program generosity and positioning within the income distribution alter our conclusions suggests that the level may not be too far from what would be optimal holding all other program parameters constant.

\section{Conclusion}

We develop three basic insights into the desirability of increasing DI benefits from our baseline analysis. First, while the indirect costs of benefit increases appear substantial, the value attached to such increases for the typical worker is also substantial. Given our estimated average implicit price of $\$ 1.50$, representative workers of all education levels should be willing to purchase an additional $\$ 1$ of disability insurance under moderate levels of risk aversion. Second, while the moral hazard costs appear to be relatively low, the implicit price of additional insurance can be quite large for some subgroups of the population due to redistribution. The implicit price of an additional dollar varies from less than $\$ 1$ for individuals with less than a high school degree to more than $\$ 7$ for individuals with a college degree. While the importance of redistribution across broad education categories has not been previously quantified, this pattern in implicit prices is not surprising given differences in the incidence of disability.

Our final conclusion is the least acknowledged and perhaps most surprising. We find 
that an increase in benefits leads to transfers from lower income individuals and states of the world to individuals and states with more moderate income, such that these transfers lead to net welfare losses at high levels of risk aversion. From an individual insurance perspective, a marginal increase in DI benefits is less attractive because of this potential redistribution to bad states from worse states. From a social perspective, inequality aversion also plays a role. This highlights that DI treats disability as a more "deserving" cause of low income than other negative shocks that affect able-bodied individuals, and that the disabled are treated as more deserving than the non-disabled poor. The incompleteness of the safety net could to lead to similar counterintuitive findings for analyses of the adequacy of other categorical social insurance programs as well.

Though our initial finding is that individuals are, if anything, over-insured against the subset of career-ending disabilities covered by DI, it is important to remember that we are evaluating a marginal change in benefit generosity. These results are derived in the context of a program that provides generous benefits to low income workers who qualify. Our estimates of willingness to pay make it clear that individuals would/should place a high value on the existence of the program. Thus, an analysis that began from a base of less generous replacement rates would be expected to reach different conclusions. The fact that we do indeed reach the opposite conclusion about the adequacy of the income security provided by DI under the alternative model that incorporates health insurance, which alters effective replacement rates, highlights this point. Though our tools do not allow us to say much about the optimal level of DI benefits, this sensitivity of our results may imply that the current level is in the neighborhood of what would be conditionally optimal.

Appendix A: Implementation in the CPS

\section{A.1 Identifying current beneficiaries}


Since the CPS does not explicitly identify which individuals are DI recipients, we need to impute DI beneficiary status. This is fairly straightforward for the working aged population. We assume that individuals aged 21 to 61 who report having a work limitation and who receive Social Security benefits are receiving those benefits on the basis of their disability. This imputation appears to be fairly accurate, capturing over $96 \%$ of the number of recipients reported in the Social Security Bulletin administrative data for $1990 .^{35}$ Table A1 summarizes the characteristics of DI beneficiaries relative to working aged individuals. For both men and women, DI beneficiaries are over 50\% more likely to be Black than other working aged individuals, and tend to be older and have lower levels of education. These types of demographic differences are important factors in the redistribution that exists within the DI program.

The process of identifying current beneficiaries is more difficult for individuals over the age of 61. We would like to identify those who were receiving DI benefits during their working years, before the disability and retirement programs merge. However, for those over 61, it is impossible to distinguish Social Security Disability Income from Social Security retirement income. In addition, since self-reported disability rates increase with age, they cannot be used effectively to determine which individuals were DI beneficiaries during their working years. Rather than identify a subset of elderly individuals as DI beneficiaries with certainty, we impute the probability that each elderly individual would have been a DI beneficiary by assuming that elderly DI beneficiaries are similar to the younger working aged beneficiaries already identified.

In order to calculate this probability, we relate whether individuals aged 51-61 are worker beneficiaries to their individual characteristics, using a logit specification run separately by gender. Results from these regressions can be found in the first two columns in Table A2. We then use the coefficients from these regressions to predict the probability that individuals aged 62 and over are DI recipients, calculated by setting their age to 61 . Any individual who does not report Social Security income is assumed to have a zero probability of DI receipt. ${ }^{36}$ Assuming similar mortality rates across disabled and non-disabled individuals, the probabilities are rescaled proportionately so that the fraction of the population imputed to be DI recipients at any age over 61 is the same as the fraction at age 61 (7.6\% for males and $6.5 \%$ for females). ${ }^{37}$ Of the 22,966 individuals in our sample over the age of $61,14,842$ are assigned a non-zero probability of being a DI beneficiary. Summary statistics for the elderly population as a whole and for imputed beneficiaries are found in Table A3.

Since family DI payment amounts are poorly reported in the CPS, we estimate these amounts for both types of current beneficiaries. All working aged beneficiaries in our sample receive DI benefits on their own account (that is, due to their own disability and

\footnotetext{
${ }^{35}$ The Bulletin documents 2,479,270 worker beneficiaries aged 21-61 in 1990. Weighting the count of imputed beneficiaries by the CPS person weight yields an estimate of 2,387,258.

${ }^{36}$ If a family has more than one elderly individual, we assume that only the individual with the highest predicted probability has a non-zero probability of being a DI recipient. We assign the probability that either is a DI recipient to this individual.

${ }^{37}$ In fact, mortality rates among DI beneficiaries tend to be higher than mortality rates among the newly retired. Thus, our assumption is likely to exaggerate the fraction of the elderly who would have been DI recipients. Calculations using existing estimates of the mortality rate among DI beneficiaries suggest the magnitude of this effect is small.
} 
work history), so we impute family benefits for them based on the reported level of worker benefits and the rules followed by the Social Security system. Our methodology yields an estimated total of $\$ 13.8$ billion in DI benefits, as compared with the value of $\$ 17.3$ billion determined from the administrative data reported by the Social Security Bulletin. To account for the apparent underreporting in the CPS, we scale reported benefits by a factor of $1.25 .^{38}$

All elderly individuals assigned a positive probability of being a DI beneficiary report receiving Social Security income. However, only some fraction is receiving benefits due to own work history. We use data on marital history, relative earnings, and gender to determine which individuals are likely to fall into this category. For these individuals, we impute family DI benefits based on reported Social Security benefits. ${ }^{39}$

\section{A.2 Identifying Marginal Applicants}

We rely on strong assumptions to identify those who would be induced to apply under the new regime. Among working aged individuals, we assume that the pool of potential applicants consists of all persons who self-report having disability-related work limitations but who are not identified as current DI beneficiaries. ${ }^{40}$ The last column for men and women in Table A1 presents summary statistics for these individuals. Among elderly individuals, we assume that the pool of potential applicants is the same as the pool of individuals imputed to have a non-zero probability of having been DI beneficiaries.

Following the regime change, each potential applicant may follow one of three paths. They may choose not to apply for DI, they may apply and be accepted to the program, or they may apply but be rejected. Each of these scenarios involves different indirect costs associated with changes in benefit outlays, labor supply, transfers, and tax payments. Rather than attribute a specific path to each individual within the potential applicant pool, we assign individuals a probability of each of these three outcomes.

In order to predict the likelihood of each of these three scenarios, we first must determine how many individuals will be induced to apply by the increase in DI benefit

\footnotetext{
${ }^{38}$ The undercount of Social Security benefits in the CPS appears to affect all age levels. An equivalent scaling factor derived for the population aged 62 and over is equal to 1.21. Due to the similarity of the implied scaling factors, we apply the working aged scaling factor to all Social Security benefits for consistency.

${ }^{39}$ For those elderly who were awarded DI benefits, the DI benefit formula is used to calculate their benefit level instead of the retirement formula. However, without detailed work histories for these individuals, we are unable to use these formulas to calculate a true level of benefits under each program. Instead, we assume both DI and retirement benefits to be equal to reported Social Security benefits for those determined to be receiving benefits on their own account.

${ }^{40}$ We assume that those who do not report a limitation in the baseline are not in the pool of potential applicants. This ignores the possibility that self-reported disability might respond to changes in the parameters of DI. Previous work has suggested that the fraction of the working aged population identifying themselves as unable to work is quite sensitive to the availability and generosity of disability benefits, but that the fraction identifying themselves as in some way limited in their capacity for work is much less sensitive to such factors (Waidmann et al 1995).

We exclude limited individuals who report SSI receipt since these individuals would have had to have passed the same screening used for DI recipients and must have been determined to be ineligible for DI due to inadequate work history. While true in general, this ignores the possibility that some SSI recipients are in the process of applying for DI.
} 
generosity, and how many of those applications will be successful. As described in the text, we assume that a $1 \%$ increase in benefits leads to a $0.5 \%$ increase in applications and that the steady state number of applicants is approximately double the number of recipients. Given these assumptions, the average probability that a limited working aged individual applies in response to a $1 \%$ increase in benefits is $.01 \times .5 \times(2 \times \mathrm{D}) / \mathrm{L}$, where $\mathrm{D}$ is the number of current beneficiaries and $\mathrm{L}$ is the number of limited non-beneficiaries. To account for individual differences in this proclivity across individuals, we adjust the above probability using information on the likelihood that limited individuals with differing observable characteristics are on DI. ${ }^{41}$ The resulting estimates of the probability of applying rely on the assumption that marginal applicants are observably similar to current recipients.

For elderly individuals, the probability of applying is derived directly from the imputed likelihood that the individual is a current DI beneficiary. We scale the probability that an elderly individual is a current DI beneficiary by $.01 \times .5 \times 2$ to take into account the magnitude of the benefit increase, the application elasticity, and the likelihood of acceptance.

With estimates of the likelihood that an individual is induced to apply on hand, we derive the likelihood of each outcome for a potential applicant. If we define the probability that an applicant applies as $a_{i}$, then, given our assumption that half are accepted, the probabilities of applying and being accepted and of applying and being rejected are both equal to $.5 \times a_{i}$. The likelihood of not applying is simply $\left(1-a_{i}\right)$.

In the event the application is successful, the person is eligible to receive some amount of DI payments. Since the CPS does not include earnings histories, we need to predict the level of payments these individuals receive. We regress actual log payments to current working-aged beneficiaries on their individual characteristics by gender (regression results can be found in columns 5 and 6 of Table A2), and then use the resulting coefficients to predict individual payments for our marginal working aged applicants. We then use the program rules to simulate family benefits. For elderly potential applicants, we use the same calculation as for elderly potential recipients, which ignores changes in benefit payments that would result from altered work histories.

\footnotetext{
${ }^{41}$ We multiply the average probability by a term that is equal to that individual's predicted likelihood of being on DI relative to the average probability among the limited non-recipient population. This term is derived from the results of logit regressions predicting DI receipt among limited individuals separately by gender (See columns 3 and 4 in Table A2).
} 
Table A1. Summary Statistics for the Working-Aged Population (21-61 years)

\begin{tabular}{|c|c|c|c|c|c|c|}
\hline \multirow[b]{3}{*}{ Black } & \multicolumn{3}{|c|}{ Males } & \multicolumn{3}{|c|}{ Females } \\
\hline & $\begin{array}{l}\text { Non-Limited } \\
\text { Individuals }\end{array}$ & $\begin{array}{c}\text { DI } \\
\text { Beneficiaries }\end{array}$ & $\begin{array}{c}\text { Potential } \\
\text { Applicants }\end{array}$ & $\begin{array}{l}\text { Non-Limited } \\
\text { Individuals }\end{array}$ & $\begin{array}{c}\text { DI } \\
\text { Beneficiaries }\end{array}$ & $\begin{array}{l}\text { Potential } \\
\text { Applicants }\end{array}$ \\
\hline & 0.105 & 0.174 & 0.160 & 0.122 & 0.225 & 0.151 \\
\hline American Indian & 0.005 & 0.010 & 0.010 & 0.006 & 0.015 & 0.010 \\
\hline Asian & 0.028 & 0.010 & 0.018 & 0.031 & 0.013 & 0.019 \\
\hline Hispanic & 0.086 & 0.061 & 0.095 & 0.082 & 0.058 & 0.068 \\
\hline Age & $\begin{array}{c}37.9 \\
(10.9)\end{array}$ & $\begin{array}{c}46.3 \\
(10.9)\end{array}$ & $\begin{array}{c}43.1 \\
(11.2)\end{array}$ & $\begin{array}{c}38.2 \\
(11.0)\end{array}$ & $\begin{array}{c}48.4 \\
(10.7)\end{array}$ & $\begin{array}{c}42.5 \\
(11.0)\end{array}$ \\
\hline Years of Education & $\begin{array}{l}13.3 \\
(2.9)\end{array}$ & $\begin{array}{l}10.4 \\
(3.9)\end{array}$ & $\begin{array}{l}11.9 \\
(3.1)\end{array}$ & $\begin{array}{l}13.1 \\
(2.7)\end{array}$ & $\begin{array}{l}10.6 \\
(3.8)\end{array}$ & $\begin{array}{l}12.3 \\
(2.9)\end{array}$ \\
\hline Married & 0.631 & 0.465 & 0.566 & 0.643 & 0.332 & 0.513 \\
\hline Never Married & 0.257 & 0.340 & 0.237 & 0.186 & 0.223 & 0.161 \\
\hline $\begin{array}{l}\text { Number of Children } \\
\text { Under } 18\end{array}$ & $\begin{array}{c}0.77 \\
(1.12)\end{array}$ & $\begin{array}{c}0.33 \\
(0.88)\end{array}$ & $\begin{array}{c}0.62 \\
(1.09)\end{array}$ & $\begin{array}{c}0.91 \\
(1.17)\end{array}$ & $\begin{array}{c}0.32 \\
(0.76)\end{array}$ & $\begin{array}{c}0.68 \\
(1.08)\end{array}$ \\
\hline Individual DI Benefits & - & $\begin{array}{l}7973^{\dagger} \\
(3854)\end{array}$ & $\begin{array}{l}7383^{\dagger} \\
(1521)\end{array}$ & - & $\begin{array}{l}6254^{\dagger} \\
(3088)\end{array}$ & $\begin{array}{l}5708^{\dagger} \\
(1003)\end{array}$ \\
\hline Family DI Benefits & - & $\begin{array}{l}9016^{\ddagger} \\
(5097)\end{array}$ & $\begin{array}{l}8624^{\ddagger} \\
(2622)\end{array}$ & - & $\begin{array}{l}7448^{\ddagger} \\
(4640)\end{array}$ & $\begin{array}{l}6787^{\ddagger} \\
(1713)\end{array}$ \\
\hline $\begin{array}{l}\text { Probability Induced to } \\
\text { Apply }\end{array}$ & - & - & $\begin{array}{c}0.005^{\ddagger} \\
(0.002)\end{array}$ & - & - & $\begin{array}{c}0.004^{\sharp} \\
(0.002)\end{array}$ \\
\hline Number of observations & 38561 & 816 & 1776 & 41946 & 618 & 1651 \\
\hline $\begin{array}{l}\text { Notes: The mean and standard } \\
\text { individuals aged 21-61 years i } \\
\text { individuals. The second colun } \\
\text { work limitation and report Soc } \\
\text { receiving Social Security inco } \\
\text { person weight. }{ }^{+} \text {The reported } \\
\text { or predicted values, using the }\end{array}$ & $\begin{array}{l}\text { ation are showr } \\
\text { March } 1991 \mathrm{Cl} \\
\text { ports statistics } \mathrm{f} \\
\text { ecurity receipt) } \\
\text { dividuals who } \\
\text { idual DI benefi } \\
\text { dus described ir }\end{array}$ & $\begin{array}{l}\text { ey characteris } \\
\text { included in th } \\
\text { lividuals who } \\
\text { third column } \\
\text { ssume are with } \\
\text { e been scaled } \\
\text { ext. }\end{array}$ & $\begin{array}{l}\text { the working } \\
\text { ple. The firs } \\
\text { puted to be c } \\
\text { statistics fo } \\
\text { pool of pote } \\
25 \% \text { to acco }\end{array}$ & $\begin{array}{l}\text { population, br } \\
\text { nn in each pan } \\
\text { DI worker ber } \\
\text { iduals who rep } \\
\text { oplicants. Obs } \\
\text { underreportin }\end{array}$ & $\begin{array}{l}\text { lown by gende } \\
\text { orts statistics } 1 \\
\text { aries (i.e. indiv } \\
\text { work limitatio } \\
\text { ons are weight } \\
\text { he CPS. "Thes }\end{array}$ & $\begin{array}{l}\text { DI status. All } \\
\text { e-bodied } \\
\text { who report a } \\
\text { re not currently } \\
\text { ng the CPS } \\
\text { ither calculated }\end{array}$ \\
\hline
\end{tabular}


Table A2. Predicting DI Participation and Payment Levels

\begin{tabular}{|c|c|c|c|c|c|c|}
\hline & \multicolumn{2}{|c|}{$\begin{array}{l}\text { Likelihood Elderly Individuals } \\
\text { are DI Beneficiaries }\end{array}$} & \multicolumn{2}{|c|}{$\begin{array}{l}\text { Likelihood Limited Working- } \\
\text { Aged Individuals are DI } \\
\text { Recipients }\end{array}$} & \multicolumn{2}{|c|}{$\begin{array}{c}\text { Predicting Individual DI } \\
\text { Payments for Working-Aged } \\
\text { Recipients }\end{array}$} \\
\hline & Males & Females & Males & Females & Males & Females \\
\hline & $(1)$ & $(2)$ & $(3)$ & $(4)$ & $(5)$ & (6) \\
\hline Constant & $\begin{array}{l}-4.616 \\
(1.077)\end{array}$ & $\begin{array}{l}-6.550 \\
(1.110)\end{array}$ & $\begin{array}{l}-3.475 \\
(0.835)\end{array}$ & $\begin{array}{l}-1.837 \\
(0.379)\end{array}$ & $\begin{array}{c}8.345 \\
(0.146)\end{array}$ & $\begin{array}{l}7.078 \\
(0.549)\end{array}$ \\
\hline Black & -- & $\begin{array}{c}0.617 \\
(0.167)\end{array}$ & $\begin{array}{l}-0.246 \\
(0.152)\end{array}$ & -- & $\begin{array}{l}-0.116 \\
(0.058)\end{array}$ & -- \\
\hline American Indian & $\begin{array}{c}0.604 \\
(0.414)\end{array}$ & $\begin{array}{l}1.307 \\
(0.470)\end{array}$ & -- & -- & -- & -- \\
\hline Asian & $\begin{array}{l}-1.844 \\
(0.798)\end{array}$ & -- & $\begin{array}{l}-0.751 \\
(0.465)\end{array}$ & -- & $\begin{array}{c}0.390 \\
(0.112)\end{array}$ & -- \\
\hline Hispanic & $\begin{array}{l}-0.853 \\
(0.232)\end{array}$ & $\begin{array}{l}-0.553 \\
(0.262)\end{array}$ & $\begin{array}{l}-0.701 \\
(0.159)\end{array}$ & $\begin{array}{l}-0.475 \\
(0.192)\end{array}$ & -- & -- \\
\hline Age & $\begin{array}{c}0.062 \\
(0.018)\end{array}$ & $\begin{array}{c}0.081 \\
(0.018)\end{array}$ & $\begin{array}{c}0.128 \\
(0.038)\end{array}$ & $\begin{array}{c}0.041 \\
(0.006)\end{array}$ & $\begin{array}{c}0.006 \\
(0.002)\end{array}$ & $\begin{array}{c}0.051 \\
(0.023)\end{array}$ \\
\hline $\begin{array}{l}\text { Age Squared (coefficient } \\
\times 100)\end{array}$ & -- & -- & $\begin{array}{l}-0.107 \\
(0.043)\end{array}$ & -- & -- & $\begin{array}{l}-0.054 \\
(0.025)\end{array}$ \\
\hline Years of Education & $\begin{array}{l}-0.071 \\
(0.067)\end{array}$ & $\begin{array}{l}-0.010 \\
(0.070)\end{array}$ & $\begin{array}{l}-0.080 \\
(0.014)\end{array}$ & $\begin{array}{l}-0.087 \\
(0.015)\end{array}$ & $\begin{array}{l}-0.014 \\
(0.016)\end{array}$ & $\begin{array}{l}-0.012 \\
(0.025)\end{array}$ \\
\hline $\begin{array}{l}\text { Years of Education } \\
\text { Squared }\end{array}$ & $\begin{array}{l}-0.007 \\
(0.003)\end{array}$ & $\begin{array}{l}-0.008 \\
(0.004)\end{array}$ & -- & -- & $\begin{array}{c}0.002 \\
(0.001)\end{array}$ & $\begin{array}{c}0.003 \\
(0.001)\end{array}$ \\
\hline Married & -- & -- & -- & $\begin{array}{l}-0.757 \\
(0.122)\end{array}$ & -- & $\begin{array}{l}-0.077 \\
(0.059)\end{array}$ \\
\hline Never Married & $\begin{array}{c}0.547 \\
(0.204)\end{array}$ & $\begin{array}{c}0.542 \\
(0.229)\end{array}$ & $\begin{array}{c}0.570 \\
(0.140)\end{array}$ & $\begin{array}{c}0.267 \\
(0.151)\end{array}$ & $\begin{array}{l}-0.311 \\
(0.059)\end{array}$ & $\begin{array}{l}-0.117 \\
(0.080)\end{array}$ \\
\hline $\begin{array}{l}\text { Number of Children } \\
\text { Under } 18\end{array}$ & -- & -- & $\begin{array}{l}-0.145 \\
(0.066)\end{array}$ & $\begin{array}{l}-0.157 \\
(0.070)\end{array}$ & -- & -- \\
\hline Number of Observations & 7990 & 8741 & 2872 & 2871 & 816 & 618 \\
\hline
\end{tabular}


and females aged 21-61 with work limitations, where the dependent variable is equal to 1 if the individual is a worker beneficiary. Columns 5 and 6 report the results form ordinary least squares regressions of the logarithm of reported individual DI benefits for male and female DI beneficiaries aged 21-61. Each observation is weighted by the CPS person weight and the standard errors are corrected using White's generalized method. Observable characteristics that did not enter significantly were dropped from the regressions since our goal is to obtain the best prediction. 
Table A3. Summary Statistics for the Elderly Population (62+ years)

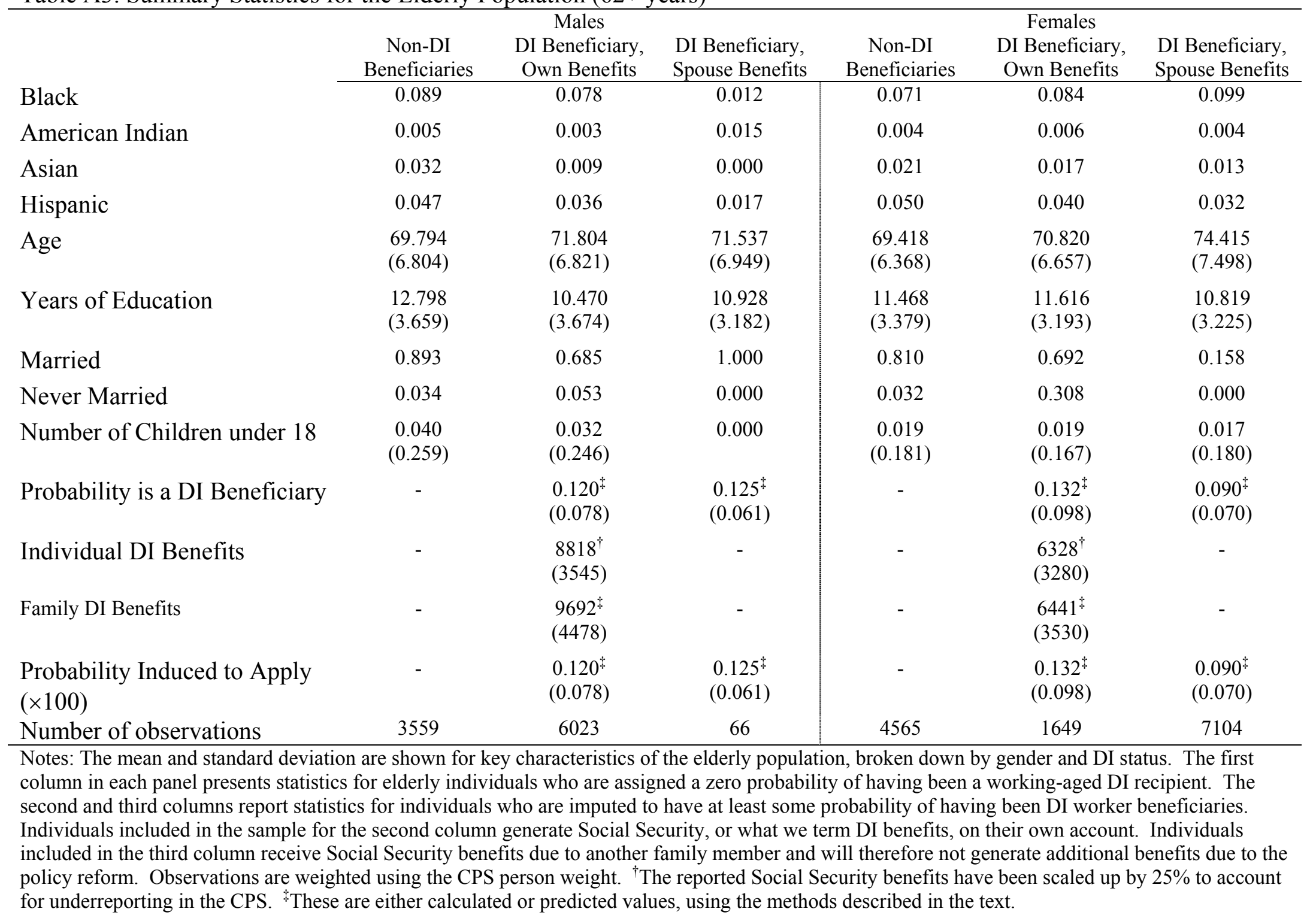


In order to identify the impact of successful and unsuccessful applications for DI benefits, we combine information on individuals who are observed in the SIPP either at some point before applying, during the application process, or at some point after to create a pseudo panel. Our regression framework allows us to track changes in key variables around the time of initial application relative to a control group of similar individuals with work limitations who never apply. Our approach will, if anything, tend to overstate the causal impact of application since some of the change is likely due to the onset of disability. The data and specification used in these regressions are discussed in the next two sections. In the third and fourth sections, we discuss the results and how the behavioral responses are incorporated in our simulations.

\section{B.1 Data}

The Surveys of Income and Program Participation (SIPP) are a series of United States Census panel surveys of representative populations of the United States. New panels were fielded in 1990, 1991, 1992, and $1993 .^{42}$ For the 1990 SIPP panel, the Census interviewed a new rotation group each month for four months starting in February 1990. These groups were interviewed eight times at four-month intervals. Each interview contains monthly information for the preceding four months. Hence, the 1990 SIPP panel provides monthly data for up to 32 months on each individual covering a 35-month period from October 1989 through August 1992. The 1991 SIPP panel was fielded using the same panel design, and in 1992 and 1993 a similar design including an additional ninth wave of interviews was used to provide a total of 36 months of data.

We match the 1990-1993 SIPP panels to the Social Security disability determination records. The records are from Disability Determination Service (DDS) and Administrative Law Judge (ALJ) stages of the determination process for those who applied for DI benefits. We have information for individuals whose applications were acted upon between 1986 and 1994 for the 1990 and 1991 panels and between 1977 and 1997 for the 1992 and 1993 panels. ${ }^{43}$ We use only those administrative records that begin with an initial consideration or reconsideration by the DDS and contain valid date of birth, filing date, and decision date information. The matching procedure produced a total of 5,594 SIPP respondents who are identified as having applied for DI, with the bulk of the applications occurring during the late 1980s and 1990s.

In what follows, we consider only the first application date observed in the administrative records for each respondent, and we consider only the final decision observed for that application. Thus, a respondent who is initially denied benefits but is awarded benefits at a later stage of the same application process will be referred to as having been awarded benefits. A respondent who is denied benefits, then later re-applies and is awarded benefits as a result of the later application, will be referred to as having been denied benefits.

\footnotetext{
${ }^{42}$ New SIPP panels were fielded in earlier and later years but not all of these data have been matched to Social Security Administration administrative records.

${ }^{43}$ These data are essentially the same as those used by Lahiri, Vaughan and Wixon (1995) and Hu, Lahiri, Vaughan and Wixon (1997) in their work studying applications to the DI and SSI programs.
} 
In our analysis, we merge our four SIPP panels but do not do so along a calendar time dimension. Instead, we focus on an event - initial application month and year for DI benefits - and array our respondent panel data by individual from the months prior to application $(t-k)$ through the months following application $(t+k)$, where $t$ is the month of application. For those who applied for benefits prior to or in the early waves of the SIPP, we have information on their household income following application. For those who applied for benefits in a middle wave, we have information on their household income in the months just prior to application and just following application. For those who applied for benefits in the later waves of the SIPP or just afterwards, we have information on their household income in the months prior to application. Using this approach, we are able to obtain snapshots of respondents' average household income in the months and years prior to and following their application for DI benefits that extend beyond the maximum of 36 months that any one respondent is followed in a given SIPP panel.

We include a control group of SIPP respondents who report having experienced a work limitation, but whom we do not identify as having applied for federal disability benefits (either DI or SSI) at any time. To ensure that we compare applicants to nonapplicants that have similar demographic characteristics, we assign weights to nonapplicants that correspond to the proportion of the DI applicant population within the relevant age, race, sex, martial status, and educational attainment cell. There are 288 separate cells in the underlying matrix, and the same number of applicants and nonapplicants are assigned to each cell when DI applicants are weighted using the given population weights and non-applicants are weighted using the newly defined weights.

\section{B.2 Empirical Specification}

We set up a regression model that allows us to estimate how a variety of income measures and indicators are affected by application. We include fixed effects for each individual, $i$, and for each calendar month, $t$, in the sample period. A set of indicator variables for months relative to application month is also included. These variables (month zero, for example, representing the month of application, or month twelve, to take another example, representing the month one year subsequent to application) are equal to one if the observation of income data is taken from the month corresponding to the indicator variable, and zero otherwise. Thus the equations have the form:

$$
y_{i t}=\alpha_{i}+\gamma_{t}+\sum_{j} \beta_{j} m_{i j}+\varepsilon_{i j}
$$

where $y_{i t}$ represents monthly income (in January 1990 dollars), an indicator for positive income, or an indicator for insurance coverage for individual $i$ in time period $t$, depending on the case. The $\alpha$ 's and the $\gamma$ 's represent applicant and calendar month fixed effects and the $m_{i j}$ 's represent the indicator variables for each month relative to the application month. There is a separate indicator variable for each month representing data from 35 months before to 39 months after application. Observations from 39 or more months prior to application or 40 or more months subsequent to application are excluded from the regression sample. Therefore, the coefficients on application month indicator variables (the $\beta$ 's) can be interpreted as the average change from the level 
observed 36 to 38 months prior to application.

Graphs in the figures that follow are constructed using estimated coefficients from regressions with the format given by equation $\left(1^{\mathrm{B}}\right)$. For purposes of presentation, the $\beta$ 's are added to average baseline incomes (technically, the average $\alpha$ for applicants). Thus, the graphs show average income from a particular source in each application month. Since a control group is included in the regressions (and application month dummies will be identically zero for all individuals in the control group), the calendar month fixed effects remove time trends resulting from age or economy-wide trends.

The time patterns for earnings, transfer receipts, and health insurance status are shown in Figures B1 through B6 for awarded and denied applicants separately by gender. The graphs in the left panel of each figure correspond to successful applicants ("awarded"), and the right-hand side panel shows the results for unsuccessful applicants ("denied"). The $y$-axis shows the average value of the variable of interest and the $x$-axis indicates the number of months relative to the time of application, with a negative sign indicating months before application. Each of the six figures is based on one of the following monthly measures: own earnings conditional on positive earnings, own labor force participation, spouse's earnings (unconditional), other transfer income (excluding AFDC, Food Stamps, and SSI), ${ }^{44}$ health insurance status, and public health insurance status.

\section{B.3 Earnings and Transfers}

In order to simulate the impact of successful and unsuccessful applications, we first use the regression results to predict how family income changes due to altered earnings and "other" transfer receipts. We then directly model changes in eligibility through the AFDC, Food Stamp, and SSI programs using the benefit algorithms for 1990. To determine changes in receipt, we rely on assumptions about post-application take-up for AFDC and SSI and apply SIPP-based estimates for the Food Stamp program. Finally, we calculate changes in state and federal income and payroll taxes paid. We address changes in public health insurance coverage in the next section.

For successful applicants, the most important behavioral response is the reduction in own labor force participation. While there is no clear trend in average earnings (conditional on working) in Figure B1, Figure B2 demonstrates that nearly all successful applicants leave the labor force permanently. For this group, there is no evidence of a significant change in average spousal earnings (Figure B3). ${ }^{45}$ Figure B4 shows that the

\footnotetext{
${ }^{44}$ Other transfer income includes state and county short-term cash, transportation, and childcare assistance.

${ }^{45}$ While this appears to be inconsistent with our assumption that wives of current beneficiaries respond to the lump sum DI payment, application to DI involves competing changes in the value of leisure and in income that apparently generate a net zero response for spouses. We report the results for unconditioned earnings since we are interested in the average effect on earnings for spouses and have less reason to expect the participation margin to be important.
} 
same holds for other transfer income for males, though there is a small (but economically insignificant) increase for females.

Therefore, to measure the public costs associated with successful applications, we first remove own earnings and add predicted DI benefits. We then calculate changes in transfers through the three specific programs that are likely to be most important. By definition, none of the marginal applicants were eligible for SSI prior to application since the screening process for the two programs is essentially the same. For successful marginal applicants with income low enough to qualify them for SSI, we assume $100 \%$ take-up. For both AFDC and Food Stamps, we observe baseline participation in the CPS and then predict eligibility post application. For the Food Stamp program, we use the matched SIPP-SSA data to estimate average take-up among eligible awarded applicants more than one year after application (57.9\%), and apply this estimate to randomly assign eligibles to the program. ${ }^{46}$ The sample is too small to generate reliable estimates of takeup for those eligible for AFDC, so we assume full take-up.

Though labor force participation rates of unsuccessful applicants drop sharply prior to the month of application, participation rebounds somewhat over time (Figure B2). For denied males, $31.8 \%$ as many are working by one year after application as were working one year before. The same estimate for females is $49.9 \%$. These rates reflect monthly participation and could be consistent with some fraction returning to work full time and some fraction returning to work part time or intermittently. In the absence of evidence on the appropriate combination, we assume the above fractions of denied applicants who are initially working in our sample return to work and that the remaining individuals leave the labor force. The figure showing the pattern in earnings over time for denied applicants (Figure B1) suggests that denied applicants who return to work earn the same as before. There is no evidence of a sizeable impact of application on either spousal labor supply or other transfers (Figures B3 and B4), so we ignore these. Finally, these individuals will not be eligible for SSI, but we handle AFDC and Food Stamps in the same way as for successful applicants, except that we use the estimated post-application Food Stamps take-up rate specific to denied applicants (59.2\%).

\section{B.4 Health Insurance Coverage}

The final two figures present the coefficients from regressions of health insurance coverage. Figure B5 graphs the coefficients on the time-since-application dummies for any health insurance coverage, while Figure B6 graphs the same for any public health insurance coverage. An individual is identified as having some form of public health insurance if the individual is covered by Medicare, Medicaid, CHAMPUS, CHAMPVA, or military health care.

Figures B5 and B6 show that successful applicants experience a dramatic increase in health insurance coverage driven by a nearly complete shift to Medicare, as would be expected since all are eligible after two years on the DI program. Unsuccessful applicants do not experience a net change in insurance coverage, though the composition of coverage shifts somewhat toward public programs. Relative to pre-application levels,

\footnotetext{
${ }^{46}$ We assume that all baseline participants who continue to be eligible continue to receive Food Stamp benefits. We then randomly determine which of the remaining eligible applicants receive Food Stamps to obtain the appropriate aggregate take-up rate.
} 
public insurance coverage rates increase by 17.6 percentage points for females and 19.6 percentage points for male by two years after application.

Determining the net fiscal externality associated with these changes is very difficult. Even individuals who are insured through private plans may be receiving subsidies from other lower cost individuals covered by the same plan. Similarly, individuals who are uninsured may impose costs on others through the system. If there is a net subsidy through health insurance or uncompensated health care prior to application, then the effective increase in the financial burden on others from any shifts to Medicare or Medicaid following application will be lower than the amount of new public outlays.

The evidence suggests that that there are sizeable subsidies through these other channels. Among workers, there appears to be some shifting of relative health care costs through reduced wages according to demographic characteristics such as age (e.g. Gruber 1994). However, there is likely to be limited wage offset according to health status (Currie and Madrian 1999). If so, privately insured marginal applicants, who are likely to be of poorer than average health, receive a subsidy equal to the difference between their medical costs and the average for workers within their age, and perhaps gender, group. While there is limited evidence regarding subsidies for the uninsured, recent estimates find that the typical uninsured individual pays only about one-third of the cost of received care (Pauly and Herring 2001).

We choose an approach that provides a clear upper bound on the new public health insurance costs associated with marginal applicants. We assume that all individuals that were not receiving public insurance prior to applying but then shift to public insurance generate net new health care costs. Since the average ratio of Medicare payments to DI family payments is $0.475,{ }^{47}$ we scale the value of DI benefits to successful applicants who were not initially publicly insured by 1.475 to incorporate Medicare costs. We assume that the fractions of denied applicants estimated to be newly covered by public health insurance generate new costs equal to per capita Medicaid expenditures in 1990 (\$6595).

\footnotetext{
${ }^{47}$ The Social Security Bulletin (1991) reports that total annual Medicare spending for DI beneficiaries was $\$ 11,239$ million in 1990 . In that same year, monthly payments to DI worker beneficiaries, their spouses, and children were $\$ 1,768$ million, $\$ 40$ million, and $\$ 162$ million, respectively.
} 
Figure B1. Applicant's Earnings (Conditional on Reporting Positive Earnings)
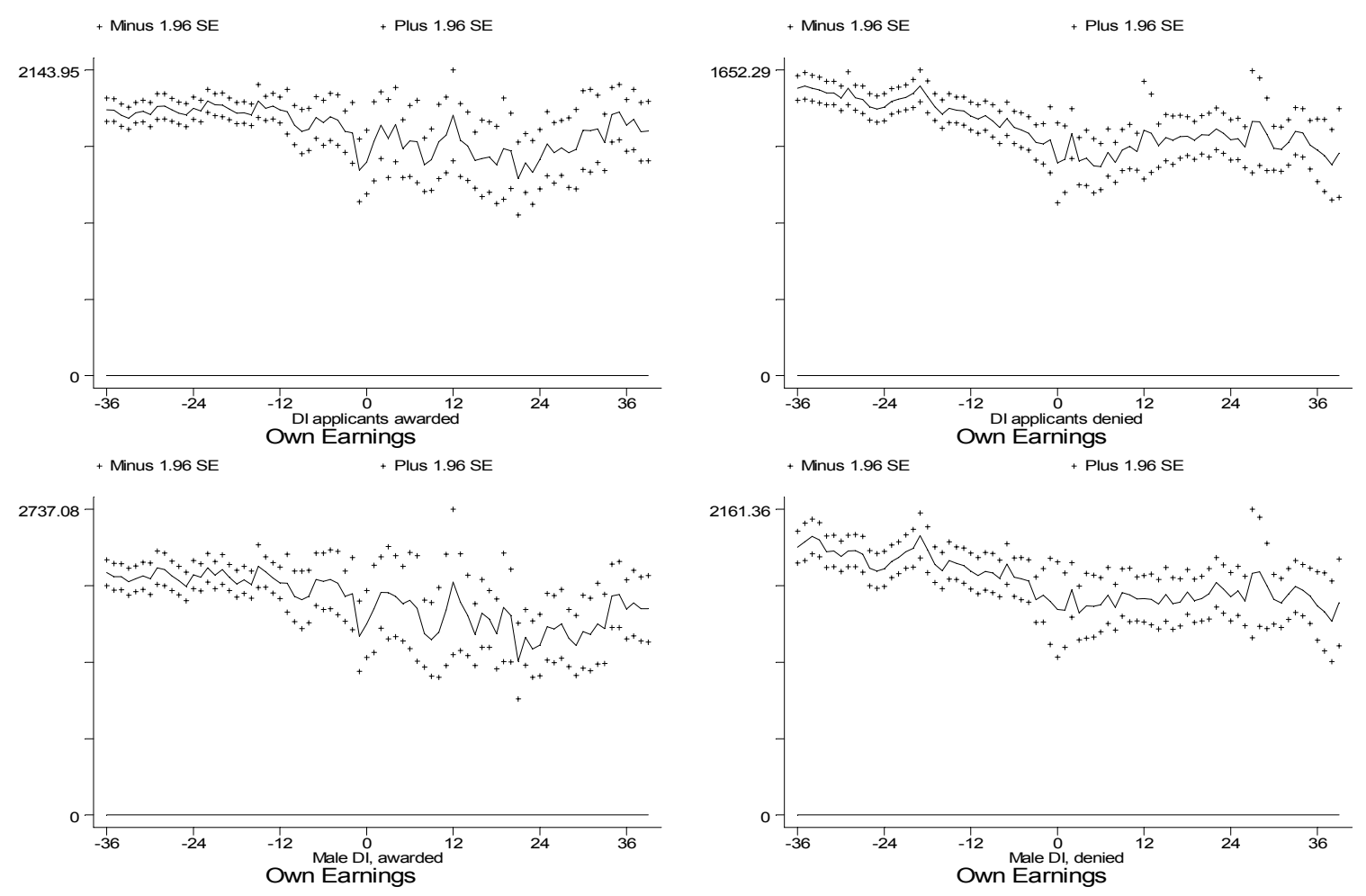

+ Minus 1.96 SE

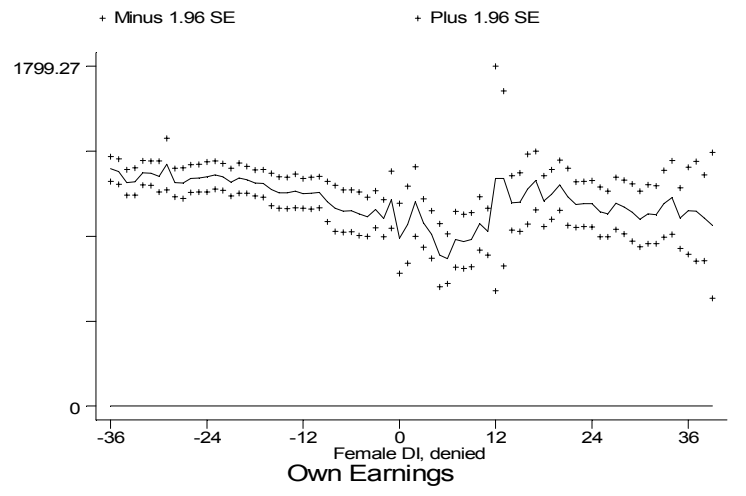


Figure B2. Applicant's Labor Force Participation
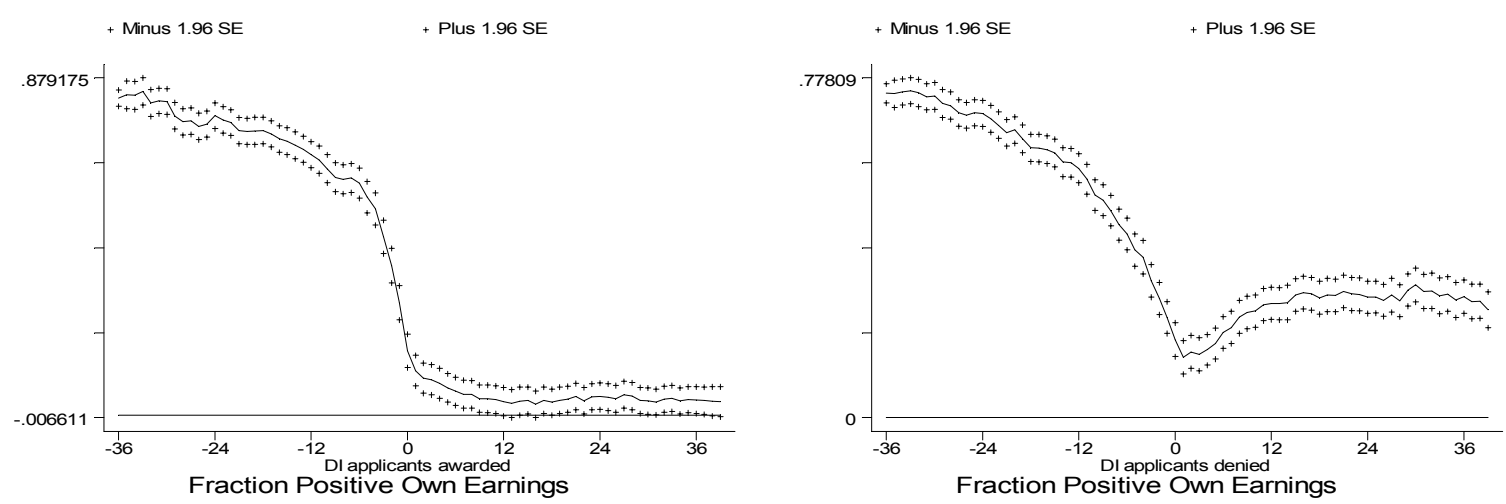

+ Minus 1.96 SE

+ Plus $1.96 \mathrm{SE}$

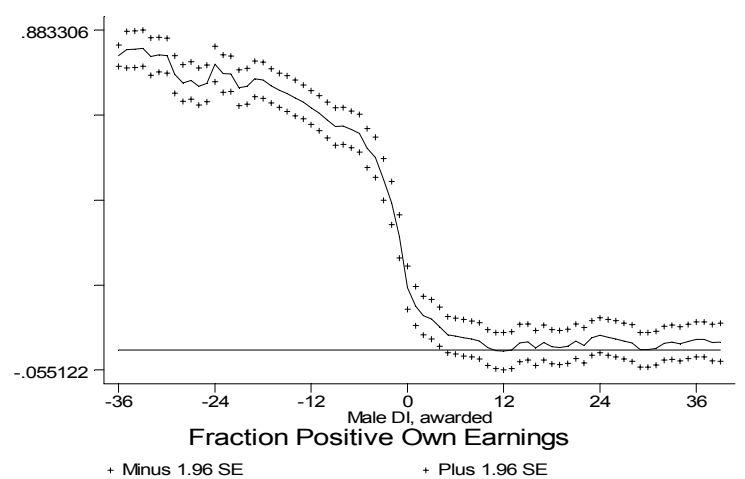

+ Minus 1.96 SE

+ Plus 1.96 SE
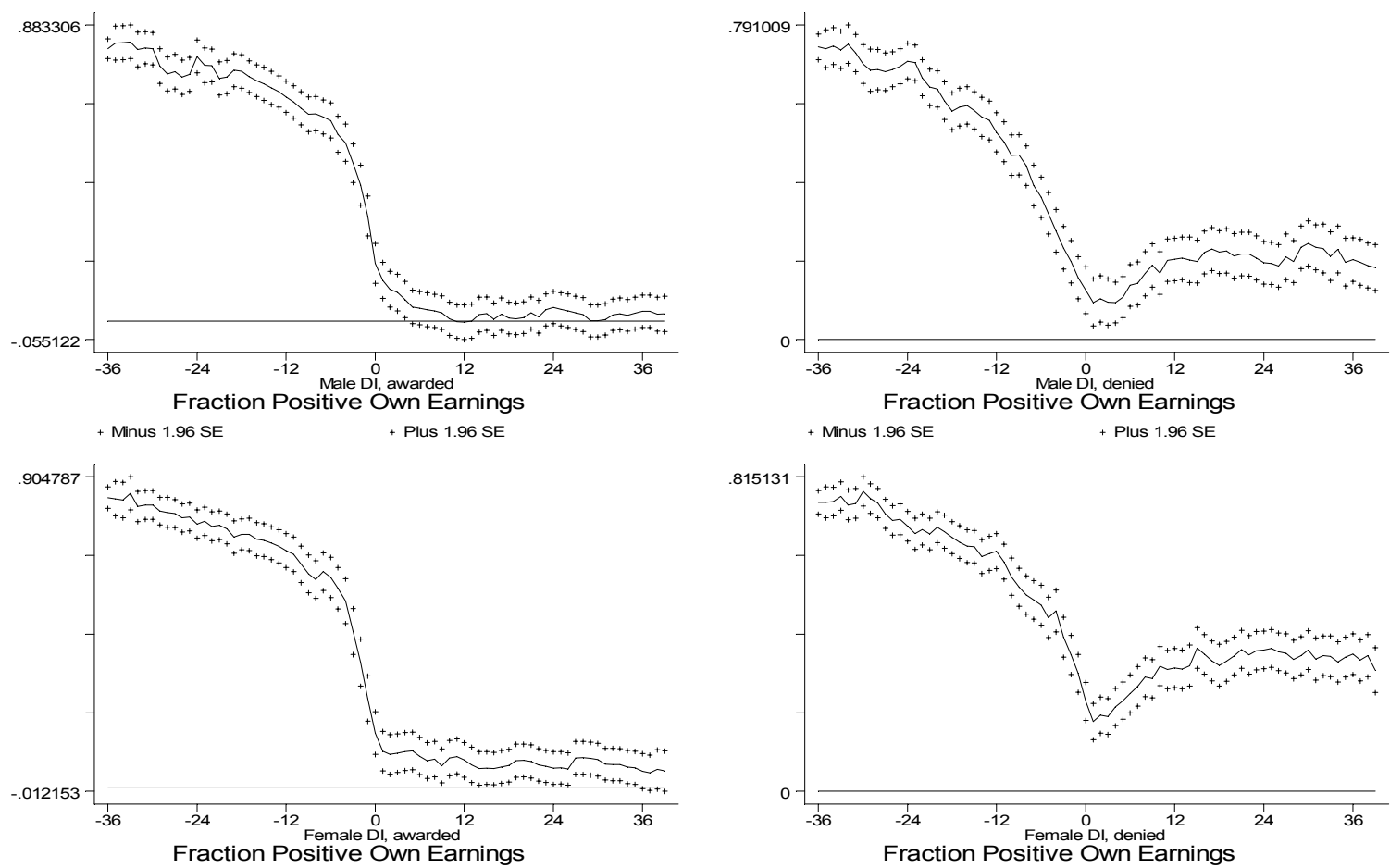
Figure B3. Applicant's Spouse's Earnings (Unconditional)
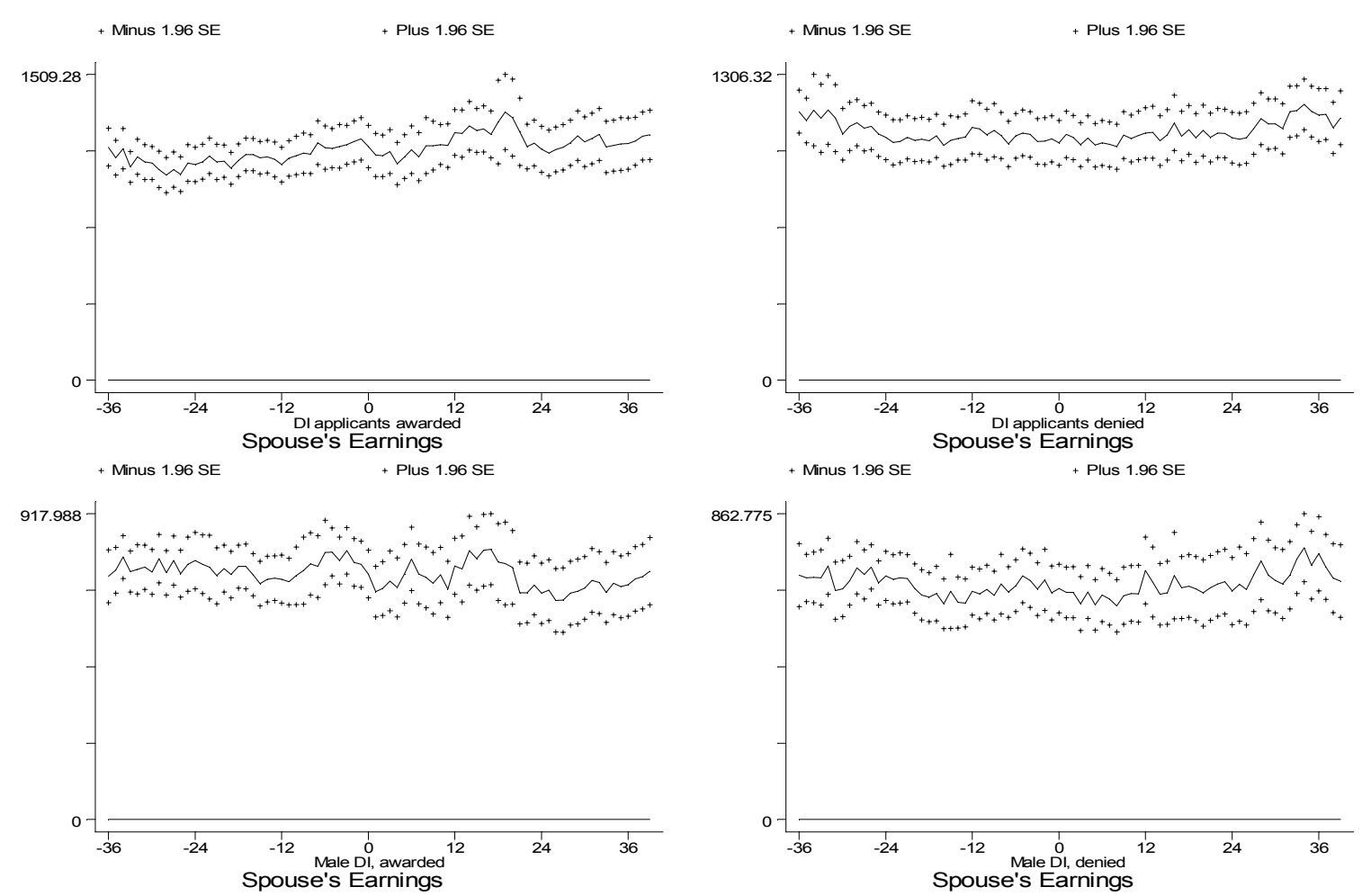

+ Minus 1.96 SE + Plus $1.96 \mathrm{SE}$
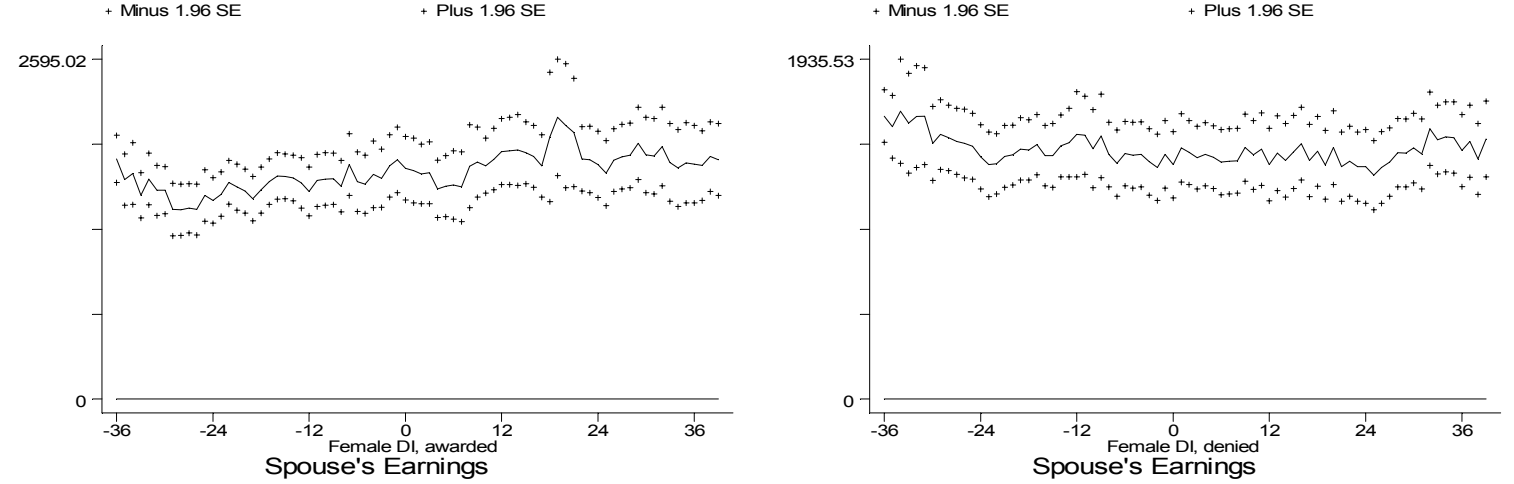
Figure B4. Applicant's Transfer Income Excluding AFDC, Food Stamps, and SSI
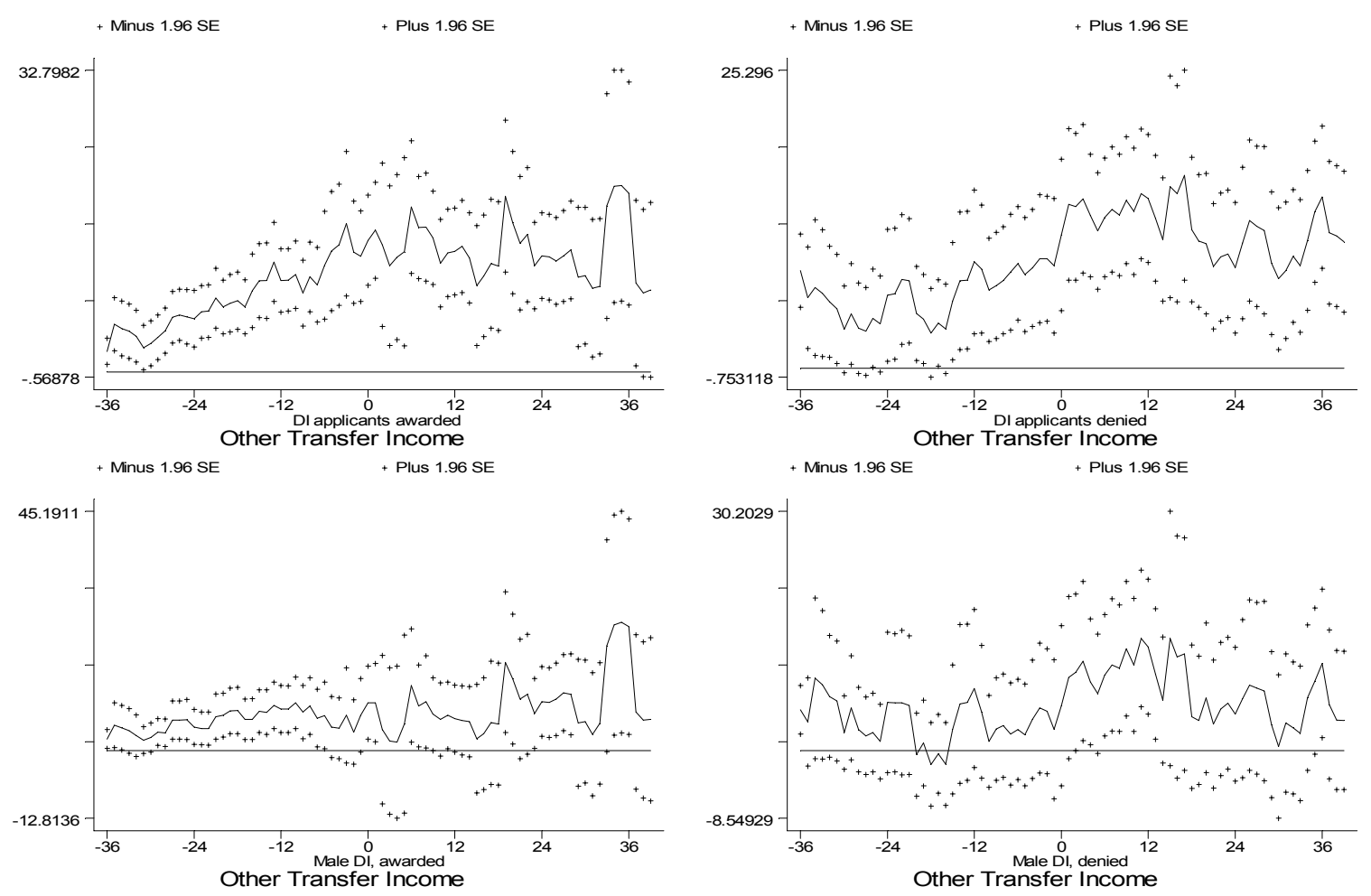

+ Minus 1.96 SE + Plus 1.96 SE + Minus 1.96 SE + Plus 1.96 SE
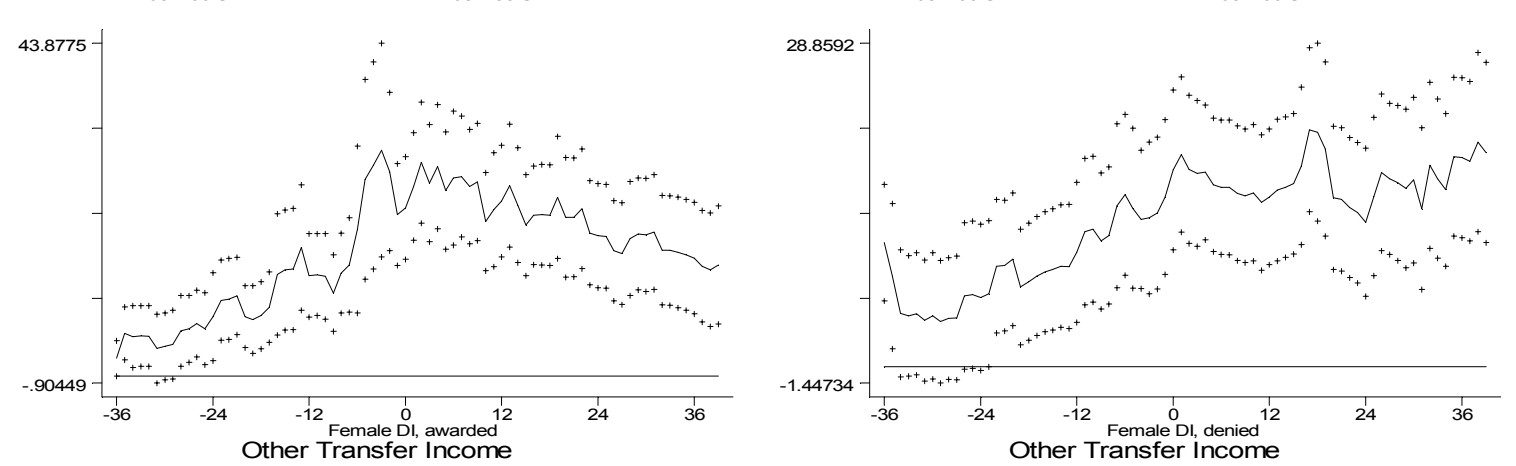
Figure B5. Applicant's Health Insurance Status
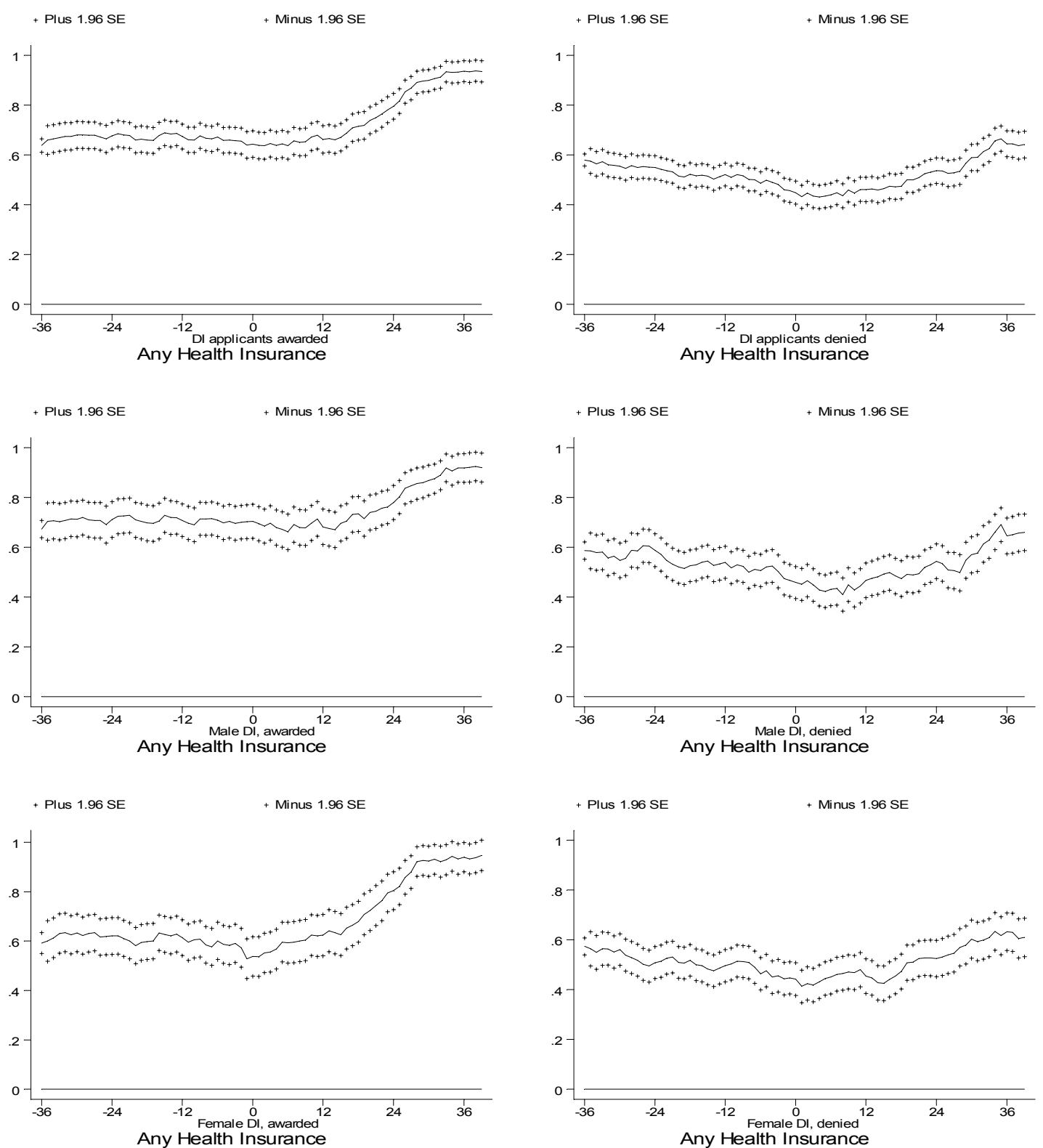
Figure B6. Applicant's Public Health Insurance Status
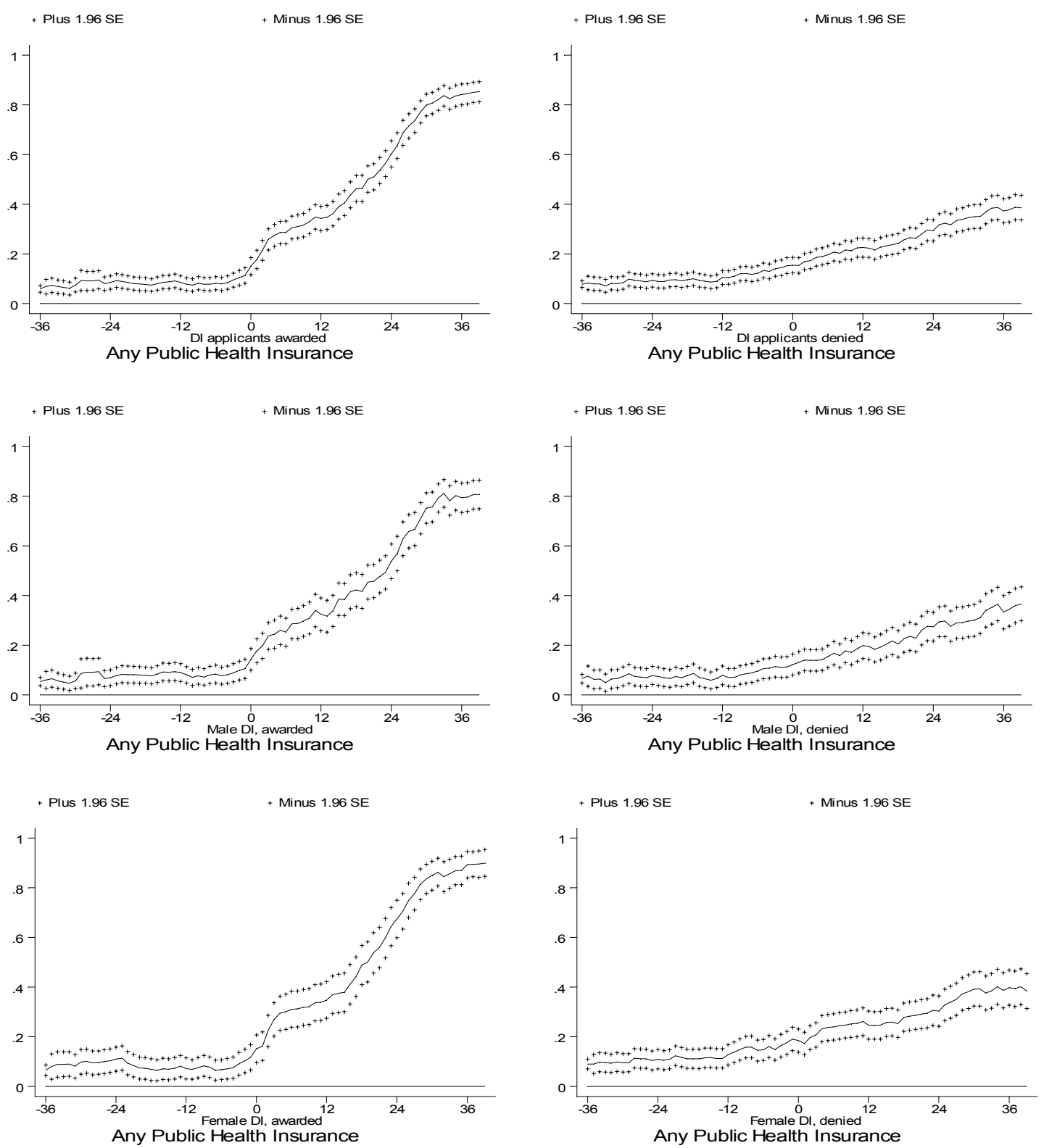
Appendix C: Predicting Family Consumption

We would like to account for the fact that variation in the distribution of income overstates variation in consumption since households can use savings and other means to smooth transitory shocks to income. Therefore, we estimate the relationship between consumption and income from the Bureau of Labor Statistics' Consumer Expenditure Survey (CEX). We then use this relationship to adjust family income in the CPS.

\section{C.1 Data}

The CEX interviews approximately 5,000 households every quarter on a rotating basis. Households are interviewed for four consecutive quarters and then dropped from the sample. Each quarter, households provide detailed reports on expenditures by category for the prior three months. Information on income for the prior year, which coincides with the timing of annual consumption, is gathered in the final interview.

We use the family-level extracts compiled by Harris and Sabelhaus (2000). In order to provide a ten-year window around 1990, we include households interviewed from the first quarter of 1985 through the last quarter of 1995 . We restrict the sample to the subset of 40,848 households that provide complete income reports and remain in the sample for a full year. Weights are provided that adjust the national CEX weights to account for attrition by age and housing tenure. We use these adjusted weights in our analyses.

Our income measure is calculated to match after-tax income in the CPS as closely as possible. It includes all components of earned and unearned income (including Food Stamp benefits) except for payments to employees in-kind and insurance refunds, which are not available in the CPS. For the same reason, we do not subtract alimony or child support payments made by the household. After-tax income is pre-tax income less reported federal and state income and payroll taxes paid.

Our total consumption measure is comprehensive and includes expenditures on the following categories of goods and services: food, tobacco, alcohol, clothing, personal care, medical, recreation, education, household, utilities, personal business, vehicles, transportation, and non-mortgage interest payments. We include rent paid for renters and home rental equivalent value for homeowners (and exclude home maintenance and financial costs).

Both income and consumption are converted to 1990 dollars using the CPI for all goods. Mean annual after-tax income in the CEX sample is $\$ 27,930$ (with a standard error of $\$ 110)$, which is somewhat higher than the mean for our CPS sample (\$23,597 (\$70)). This difference can at least be partly explained by the fact that the CEX familylevel data corresponds to more expansive household units than our CPS family-level data. Mean annual consumption in the CEX sample is $\$ 25,715$ ( $\$ 81)$.

\section{C.2 Predicting Consumption}

Our specification relates the natural logarithm of consumption to the natural logarithm of income and a constant term. We replace income to $\$ 1$ if income is less than $\$ 1$ and also include an indicator for these low-income households. We allow for heterogeneity in the relationship between consumption and income by age and disability status. We 
split households into three categories according to age of the household head: less than 45 years, 45-61 years, and 62 years and over. For the two non-elderly groups, we split the sample further into households with and without a disabled working-aged individual. ${ }^{48}$

We began with a specification that allowed for a full set of interactions between the other control variables and indicators for each demographic group. We could not reject the hypothesis that the slopes were the same across these five groups. While the coefficients on the low-income indicator were significantly different from one another for the groups that had low-income individuals, not all of our groups were represented. Therefore, the specification that we implement constrains the coefficient on log income and the coefficient on the low-income indicator to be the same across groups, and includes separate constant terms for each group.

The ordinary least squares results from this specification are shown below:

Table C1. Predicting Annual Consumption

\begin{tabular}{lc|cc}
\hline Independent Variable & $\begin{array}{c}\text { Sample } \\
\text { Share }\end{array}$ & Coefficient & $\begin{array}{c}\text { Standard } \\
\text { Error }\end{array}$ \\
\hline Constant & & 5.141 & 0.061 \\
Ln(annual after-tax income) & & 0.486 & 0.006 \\
Indicator for income less than \$1 & & 5.376 & 0.084 \\
Head under 45 years of age & & & \\
$\quad$ No working-aged disabled in CU & $51.0 \%$ & - & - \\
$\quad$ Working-aged disabled member & $2.5 \%$ & -0.131 & 0.019 \\
Head between 45 and 61 years of age & & & \\
$\quad$ No working-aged disabled in CU & $20.8 \%$ & 0.074 & 0.007 \\
$\quad$ Working-aged disabled member & $2.4 \%$ & -0.082 & 0.018 \\
Head aged 62+ & $23.3 \%$ & -0.036 & 0.007 \\
\hline
\end{tabular}

The dependent variable is log consumption and the omitted demographic category is household head under 45 with no working-aged disabled members. The regression is weighted using the adjusted weight. The number of observations is 40,848 and the adjusted $\mathrm{R}$-squared is 0.494 .

The coefficient on log income is surprisingly low, a robust finding that is not an artifact of pooling the sample. There is certainly a great deal of measurement error in income in the CEX that would lead to a downward bias in the estimated income elasticity. As long as measurement error in the CPS is similar to that in the CEX, then this prediction is still useful for our purposes. It is important to keep in mind, however, that applying these estimates to predict consumption in the CPS likely leads to an overly narrow distribution. One other finding that is worth noting is that disabled households apparently consume less than non-disabled households with the same income.

In order to predict consumption for our CPS sample, we apply the estimated coefficients shown in Table B1. However, we first make one adjustment. Since we conduct welfare analyses both for income and for consumption ("smoothed" income), we want to ensure that any differences in the inferences are not driven by differences in mean levels. We, therefore, redefine the constant term to equate mean income and mean predicted consumption.

\footnotetext{
${ }^{48}$ Households with working-aged disabled members are identified as households that either report SSI receipts or have no member over 61 years of age and report receiving Social Security income.
} 
Appendix D: Estimating Out-of-pocket Medical Expenditures

We model the role of health insurance in our welfare calculations through its impact on the distribution of out-of-pocket expenditures. In this appendix, we describe how we estimate this distribution for different demographic groups by insurance status.

\section{D.1 Data}

We rely on the same CEX extracts that are described in Appendix C. We combine these data with additional data on health insurance status from the detailed expenditure files on hospitalization and health insurance included in the CEX since the first quarter of 1988. From these files, we are able to identify whether any members in the household are covered by private insurance, Medicare, Medicaid, and/or another program that provides free health care (e.g. CHAMPUS or military health care). To match these quarterly data on insurance status to the annual income files, we identify a household as covered by one of these plans if any member was covered at any point during the year. Restricting the sample to households that are complete income reporters and remain in the sample for a full year, the analysis sample includes 28,718 households interviewed between the first quarter of 1988 and the last quarter of 1995 .

\section{D.2 Methodology}

We use the empirical distributions of out-of-pocket health care expenditures in the CEX to randomly reduce income for households in the CPS. We estimate the distribution separately for households with heads under 45 years, between 45 and 61 years, and over 62 years of age. We further distinguish among households within these groups by four mutually exclusive classes of insurance coverage: no insurance (12.2\%), private insurance only (52.6\%), Medicare (22.8\%), and Medicaid or any other free care program (12.4\%). The Medicare category may include individuals covered by supplementary private insurance plans. The Medicaid category includes any household covered by Medicaid, including households that are also covered by Medicare or private insurance.

Health care expenditures include expenditures on medical goods and services, as well as payments for health insurance premiums and copayments. We calculate the income share of health care expenditures by taking the ratio of expenditures to after-tax income, as calculated in Appendix C. For each of our three age groups by the four insurance statuses, we then identify the percentiles of the distribution of the income share (for every two percentiles from the $2^{\text {nd }}$ to the $98^{\text {th }}$ ) for each of our three demographic groups by the four insurance statuses. The data are weighted by the adjusted household weight for these calculations.

Each household in the CPS sample is then randomly assigned the out-of-pocket income share associated with one of the percentiles of the distribution that is appropriate to them. For the welfare calculations, we subtract from (or add to) household income the difference between the assigned health care expenditures and overall average health care expenditures. The empirical distributions from the CEX are shown in the following figures. 
Figure D1. Income Share of Out-of-pocket Health Care Expenditures for Households with Head Under 45 Years of Age
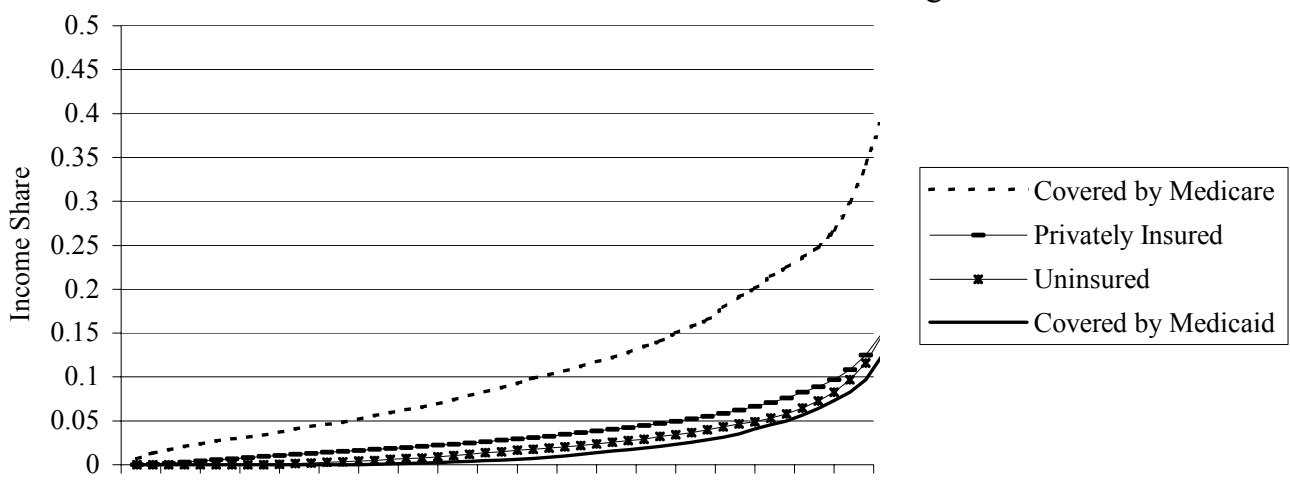

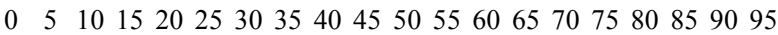

Percentile of the Distribution of the Income Share

Figure D2. Income Share of Out-of-pocket Health Care Expenditures for Households with Head 45-61 Years of Age
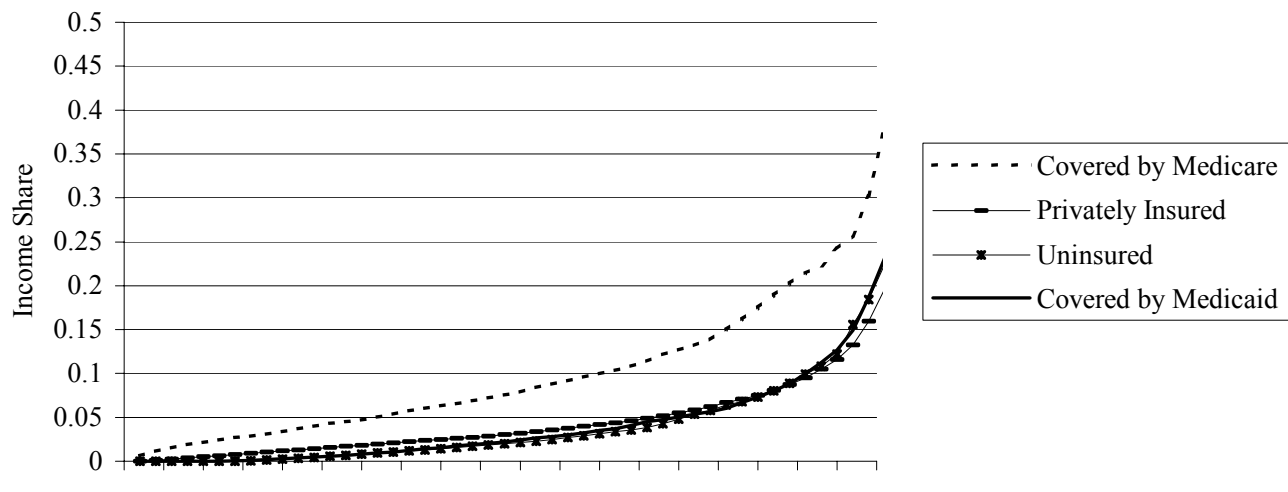

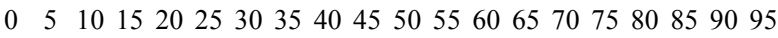

Percentile of the Distribution of the Income Share

Figure D3. Income Share of Out-of-pocket Health Care Expenditures for Households with Head Over 61 Years of Age
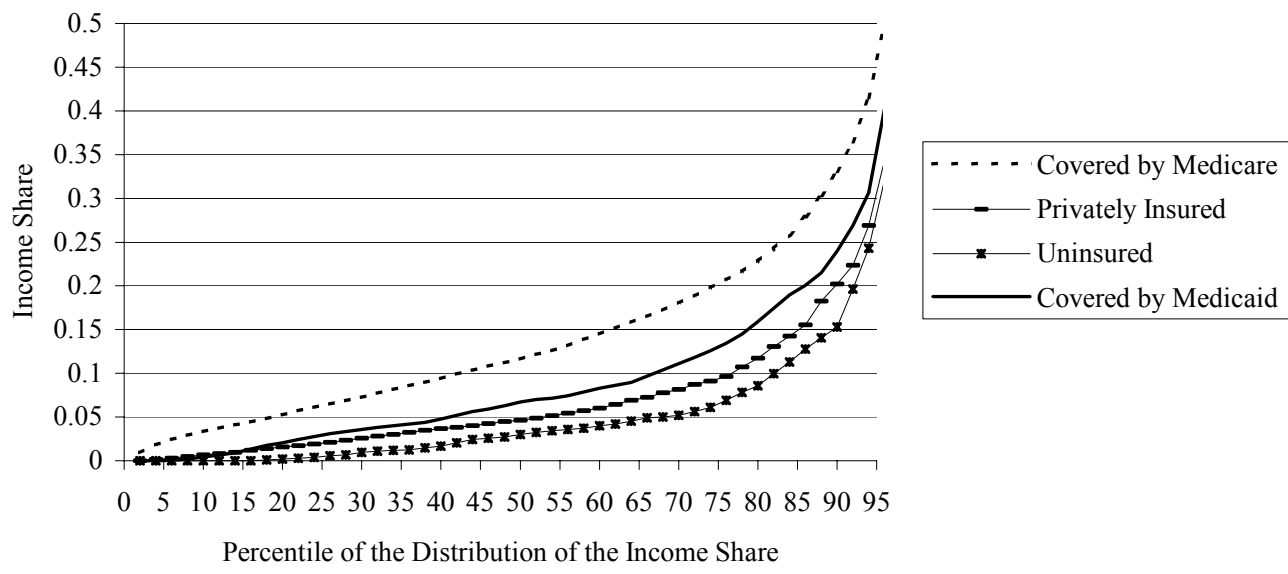


\section{References}

Anderson, Patricia M. and Bruce D. Meyer, 1995, "The Incidence of a Firm-Varying Payroll Tax: The Case of Unemployment Insurance," NBER Working Paper No. 5201 (Cambridge, MA: National Bureau of Economic Research).

Autor, David H. and Mark G. Duggan, forthcoming, "The Rise in the Disability Rolls and the Decline in Unemployment," Quarterly Journal of Economics.

Bird, Edward, 1996, "Repairing the Safety Net: Is the EITC the Right Patch?," Journal of Policy Analysis and Management 15(1) (Winter):1-31.

Barsky, Robert B., Thomas F. Juster, Miles S. Kimball and Matthew D. Shapiro, 1997, "Preference Parameters and Behavioral Heterogeneity: An Experimental Approach in the Health and Retirement Survey," Quarterly Journal of Economics, 112(2): 537-79.

Bound, John and Richard Burkhauser, 1999, "Economic Analysis of Transfer Programs Targeted on People with Disabilities" Handbook of Labor Economics, Vol. 4, Ashenfelter and Card, editors.

Bound, John and Timothy Waidmann, 1992, "Disability Transfers, Self-Reported Health, and the Labor Force Attachment of Older Men: Evidence from the Historical Record," Quarterly Journal of Economics, 107(4): 1393-1419.

Bound, John and Timothy Waidmann, 2002, "Accounting for Recent Declines in Employment Rates among the Working-aged Men and Women with Disabilities," Journal of Human Resources, 37(2) (Spring): 231-250.

Burkhauser, Richard V., Robert H. Haveman, and Barbara L. Wolfe, 1993, "How People with Disabilities Fare when Public Policies Change," Journal of Policy Analysis and Management, 12(2) (Spring): 251-269.

Citro, Constance F. and Robert T. Michael, eds., 1995, Measuring Poverty: A New Approach, Washington, D.C.: National Academy Press.

Cullen, Julie Berry and Jonathan Gruber, 2000, "Does Unemployment Insurance Crowd Out Spousal Labor Supply?,” The Journal of Labor Economics, 18(3) (July): 546-72.

Currie, Janet and Brigitte C. Madrian, 1999, "Health, Health Insurance, and the Labor Market," in Ashenfelter, Orley and David Card, eds., Handbook of Labor Economics Volume 3C (New York: Elsevier Science), 3309-3416.

Diamond, P.A. and J. A. Mirrlees, 1978, "A Model with Social Insurance with Variable Retirement," Journal of Public Economics, 10: 295-336.

Diamond, Peter and Eytan Sheshinski, 1995, "Economic Aspects of Optimal Disability Benefits," Journal of Public Economics, 57(1) (May): 1-23.

Feenberg, Daniel Richard and Elizabeth Coutts, 1993, "An Introduction to the TAXSIM Model," Journal of Policy Analysis and Management, 12(1) (Winter): 189-194.

Gruber, Jonathan, 1994, "The Incidence of Mandated Maternity Benefits," American Economic Review, 84(3) (June): 622-641.

Gruber, Jonathan, 1996, "Disability Insurance Benefits and Labor Supply,” NBER Working Paper \# 5866.

Halpern, Janice H., 1979, “The Social Security Disability Insurance Program: Reasons for Its Growth and Prospects for the Future," New England Economic Review (May/June): 30-48.

Harris, Ed and John Sabelhaus, 2000, "Consumer Expenditure Survey Family-Level Extracts, 1980:1 -- 1998:2," Congressional Budget Office, (September). 
Haveman, Robert H. and Barbara L. Wolfe, 1990, "The Economic Well-Being of the Disabled, 1962-1984," Journal of Human Resources, 25(1): 32-55.

Hu, Lahiri, Vaughan, and Wixon, 1997, "A Structural Model of Social Security's Disability Determination Process," SSA Office of Research, Evaluation, and Statistics, Working Paper \#72.

Killingsworth, Mark, 1983, Labor Supply (Cambridge and New York: Cambridge University Press).

Kreider, Brent, 1999, "Social Security Disability Insurance: Applications, Awards, and Lifetime Income Flows," Journal of Labor Economics 17(4) (October): 784-827.

Lahiri, Vaughan, and Wixon, 1995, "Modeling SSA's Sequential Disability Determination Process Using Matched SIPP Data," Social Security Bulletin, 58(4) (Winter): 3-42.

Lando, Mordechai E., Malcolm B. Coate and Ruth Kraus, 1979, "Disability Benefit Applications and the Economy," Social Security Bulletin, 42: 3-10.

Pauly, Mark and Bradley Herring, 2001, "Expanding Coverage Via Tax Credits: TradeOffs and Outcomes," Health Affairs January/February:9-26.

Stapleton, David C., Kevin Coleman, Kimberly Dietrich, and Gina Livemore, 1998, "Empirical Analysis of DI and SSI Application and Award Growth," in Kalman Rupp and David C. Stapleton, eds., Growth in Disability Benefits (Kalamazoo, MI: W.E. Upjohn Institute).

U.S. Department of Health and Human Services, Social Security Administration. 1991. Social Security Bulletin, Annual Statistical Supplement.

U.S. Senate. Committee on Finance. Hearings on the Social Security Amendments of 1955.

Varian, H. R., 1980, "Redistributive Taxation as Social Insurance," Journal of Public Economics 14:49-68.

Waidmann, Timothy, John Bound, and Michael Schoenbaum, 1995, "The Illusion of Failure: Trends in the Self-Reported Health of the U.S. Elderly," NBER Working Paper 5017. 


\begin{tabular}{lc}
\hline & $\begin{array}{c}\text { Millions of } \\
\text { Dollars }\end{array}$ \\
\cline { 2 - 2 } Net transfer to current DI recipients (static costs) & \\
& 286.3 \\
Increased DI payments to worker beneficiaries & 191.1 \\
Increased DI payments to elderly beneficiaries & 129.6 \\
Decreased SSI payments to current beneficiaries & $(28.9)$ \\
Decreased Food Stamp benefits to current beneficiaries & $(0.9)$ \\
Increase in federal taxes paid by current beneficiaries & $(4.1)$ \\
Increase in state taxes paid by current beneficiaries & $(0.5)$ \\
& \\
Costs associated with behavioral response (dynamic costs) & 143.0 \\
& \\
DI payments to successful new applicants & 89.7 \\
Expected costs due to changes in taxes paid & 53.1 \\
Decrease in federal taxes paid due to spousal labor supply response & 1.1 \\
Decrease in state taxes paid due to spousal labor supply response & 0.2 \\
Decrease in payroll taxes paid due to spousal labor supply response & 0.9 \\
Decrease in federal taxes paid by marginal applicants & 22.5 \\
Decrease in state taxes paid by marginal applicants & 5.2 \\
Decrease in payroll taxes paid by marginal applicants & 23.2 \\
Expected transfer costs (due to marginal applicants) & 0.2 \\
Change in SSI payments & 0.3 \\
Change in Food Stamp benefits & 0.4 \\
Change in AFDC payments & $(0.5)$ \\
& \\
\hline
\end{tabular}

Implicit price of an additional $\$ 1$ of insurance (total costs/static costs)

1.50

Notes: The policy reform considered is a $1 \%$ increase in the generosity of DI benefits. The static costs are the calculated costs of financing the reform in the absence of behavioral responses. The dynamic costs include costs arising due to behavioral responses of spouses of current beneficiaries and of individuals induced to apply to the program on the margin. Note that the payroll tax costs include the employer share. All costs are simulated using the March 1991 CPS. The values in bold represent totals, and the values that are not in bold are subtotals. Parentheses () are used to indicate cost savings. All values are in 1990 millions of dollars. 
Table 2. Representative Individuals' Willingness to Pay

\begin{tabular}{ccccccc} 
Earnings/ & Family DI & Pre-tax HH & After-tax HH & \multicolumn{3}{c}{ Willingness to Pay (\$) } \\
HH income & benefits/earnings & income RR & income RR & $\theta=1$ & $\theta=2$ & $\theta=4$ \\
\hline$(1)$ & $(2)$ & $(3)$ & $(4)$ & $(5)$ & $(6)$ & $(7)$ \\
\hline
\end{tabular}

All Eligible Workers

Less than High School

High School Degree

Some College

College Degree

(5)

Eligible Male Workers

Less than High School

High School Degree

Some College

College Degree

$\begin{array}{ll}0.615 & 0.477 \\ 0.558 & 0.417 \\ 0.589 & 0.370 \\ 0.634 & 0.282\end{array}$

0.724

0.714

0.829

1.21

1.46

2.12

.417

0.665

0.819

1.22

1.49

2.22

0.634

0.569

0.779

1.28

1.65

2.72

$1.45 \quad 2.09$

4.39

Eligible Female Workers

Less than High School

High School Degree

$\begin{array}{ll}0.689 & 0.490 \\ 0.660 & 0.433 \\ 0.666 & 0.378 \\ 0.681 & 0.279\end{array}$

0.690

0.657

0.691

0.616

0.535

0.808
0.784
0.742
0.655


0.869
0.854
0.824
0.765

1.24

1.53

2.35

$1.28 \quad 1.63$

2.65

$\begin{array}{ll}1.35 & 1.82\end{array}$

3.30

$1.53 \quad 2.33$

5.43

Some College

0.450

0.451

0.413

0.399

0.449

0.360

College Degree $\quad 0.483 \quad 0.283$

0.283

0.790
0.772
0.728
0.674

0.869

1.15

1.17

1.21

1.31

1.32

1.37

1.75

College Degree $\quad 0.483 \quad 0.283$

of individuals that is aged 45-61 and is eligible for DI (i.e. has not applied for DI by the time observed in the SIPP and has the requisite number of
quarters of covered earnings as reported in the SER data). We also use only the subset of these DI-eligible individuals who are observed in the $3^{\text {rd }}$ of the SIPP, so that income can be aggregated over the first full calendar year of the SIPP. We project the amount of family DI benefits that each individual would be eligible for from SER data on earnings from 1951 until the year before the individual is observed. Reported earnings as a share of total household income and family DI benefits as a share of own earnings are reported in columns 1 and 2, respectively. Column 3 shows the ratio of total family income less own earnings plus family DI benefits to total family income, which is the pre-tax replacement rate for household income. We use TAXSIM and the annual payroll tax parameters to calculate the parallel replacement rate for after-tax income. (Note that we never feed the restricted-use income data through TAXSIM. We instead feed simulated data through TAXSIM that allows us to approximate the nonlinear tax schedule, and then apply that schedule to the actual data.) The last three rows present the willingness to pay for $\$ 1$ of DI benefits at different levels of risk aversion. Given the separable constant relative risk aversion utility function presented in the text, willingness to pay is simply the ratio of the marginal utility of income in the disabled relative to the non-disabled state, which is equal to the ratio of after-tax incomes in the two states raised to the power of $-\theta$. 
Table 3. Implicit Price of Additional Insurance by Education Category

\begin{tabular}{|c|c|c|c|c|c|c|c|}
\hline & $\begin{array}{c}\begin{array}{c}\text { Static } \\
\text { Cost }\end{array} \\
(1)\end{array}$ & $\begin{array}{c}\text { Dynamic } \\
\text { Cost }\end{array}$ & $\begin{array}{c}\text { Total } \\
\text { Cost } \\
(3)\end{array}$ & $\begin{array}{c}\text { Total Cost/ } \\
\text { Income }(\times 1000) \\
(4)\end{array}$ & $\begin{array}{c}\begin{array}{c}\operatorname{Pr}(\mathrm{DI} \\
\text { Recipient) }\end{array} \\
(5)\end{array}$ & $\begin{array}{c}\text { Benefit } \\
\text { Increase } \\
(6)\end{array}$ & $\begin{array}{c}\text { Implicit } \\
\text { Price }\end{array}$ \\
\hline Less than High School & $\begin{array}{c}1.05 \\
(0.01)\end{array}$ & $\begin{array}{c}0.47 \\
(0.01)\end{array}$ & $\begin{array}{c}1.52 \\
(0.02)\end{array}$ & $\begin{array}{c}0.089 \\
(0.001)\end{array}$ & $\begin{array}{c}0.092 \\
(0.002)\end{array}$ & $\begin{array}{l}52.42 \\
(0.65)\end{array}$ & 0.32 \\
\hline High School Degree & $\begin{array}{c}2.31 \\
(0.01)\end{array}$ & $\begin{array}{c}1.09 \\
(0.01)\end{array}$ & $\begin{array}{c}3.40 \\
(0.02)\end{array}$ & $\begin{array}{c}0.145 \\
(0.001)\end{array}$ & $\begin{array}{c}0.036 \\
(0.001)\end{array}$ & $\begin{array}{l}62.96 \\
(0.77)\end{array}$ & 1.50 \\
\hline Some College & $\begin{array}{c}2.90 \\
(0.02)\end{array}$ & $\begin{array}{c}1.41 \\
(0.01)\end{array}$ & $\begin{array}{c}4.31 \\
(0.03)\end{array}$ & $\begin{array}{c}0.159 \\
(0.001)\end{array}$ & $\begin{array}{c}0.023 \\
(0.001)\end{array}$ & $\begin{array}{l}64.25 \\
(1.31)\end{array}$ & 2.92 \\
\hline College Degree & $\begin{array}{c}3.80 \\
(0.02)\end{array}$ & $\begin{array}{c}2.08 \\
(0.01)\end{array}$ & $\begin{array}{c}5.88 \\
(0.03)\end{array}$ & $\begin{array}{c}0.165 \\
(0.001)\end{array}$ & $\begin{array}{c}0.012 \\
(0.001)\end{array}$ & $\begin{array}{l}68.53 \\
(1.46)\end{array}$ & 7.15 \\
\hline \multicolumn{8}{|c|}{$\begin{array}{l}\text { Notes: The unit of observation is the family. The first two columns show the average static and dynamic costs borne by families without current } \\
\text { working-aged or elderly DI beneficiaries, separately for families broken down by education level of the head. The third column presents the average } \\
\text { total cost (sum of the static and dynamic costs) for families in each educational category, while the fourth column shows total cost as a share of baseline } \\
\text { family income (these values are multiplied by } 1000 \text { ). Column } 5 \text { shows the probability that a family has a worker or elderly DI beneficiary. Among } \\
\text { families with DI beneficiaries, column } 6 \text { shows the average increase in family benefits associated with a } 1 \% \text { increase in DI benefit generosity. The } \\
\text { increase in family benefits is net of the mechanical increase in federal and state income taxes paid and the mechanical reduction in other transfer } \\
\text { benefits. The last column shows the average of total costs divided by expected benefits across families, where the expected benefits of the policy reform } \\
\text { are calculated as the probability that a family has a current beneficiary multiplied by the expected net increase in DI payments. All results are based on } \\
\text { the } 1991 \text { March CPS with household observations weighted by the person weight of the head. Standard errors are in parentheses. }\end{array}$} \\
\hline
\end{tabular}


Table 4. Pre-reform and Post-reform Income

\begin{tabular}{|c|c|c|c|c|c|c|}
\hline \multirow[b]{4}{*}{ Family after-tax income } & \multicolumn{3}{|c|}{ Individuals in families with: } & \multicolumn{3}{|c|}{ Individuals in families with: } \\
\hline & $\begin{array}{c}\text { No DI } \\
\text { beneficiary }\end{array}$ & $\begin{array}{l}\text { DI worker } \\
\text { beneficiary }\end{array}$ & $\begin{array}{l}\text { Elderly DI } \\
\text { beneficiary }\end{array}$ & $\begin{array}{c}\text { No DI } \\
\text { beneficiary }\end{array}$ & $\begin{array}{l}\text { DI worker } \\
\text { beneficiary }\end{array}$ & $\begin{array}{l}\text { Elderly DI } \\
\text { beneficiary }\end{array}$ \\
\hline & \multicolumn{3}{|c|}{ In the base period (pre-reform): } & \multicolumn{3}{|c|}{ Change in income following the reform: } \\
\hline & $\begin{array}{l}28455 \\
(20113)\end{array}$ & $\begin{array}{c}22302 \\
(15820)\end{array}$ & $\begin{array}{c}21655 \\
(15350)\end{array}$ & $\begin{array}{l}-4.74 \\
(3.94)\end{array}$ & $\begin{array}{c}78.2 \\
(63.7)\end{array}$ & $\begin{array}{c}54.5 \\
(56.2)\end{array}$ \\
\hline $\begin{array}{l}\text { Smoothed family after-tax } \\
\text { income }\end{array}$ & $\begin{array}{l}25971 \\
(9431)\end{array}$ & $\begin{array}{l}20432 \\
(7178)\end{array}$ & $\begin{array}{l}21584 \\
(7064)\end{array}$ & $\begin{array}{l}-2.00 \\
(1.31)\end{array}$ & $\begin{array}{l}38.5 \\
(27.5)\end{array}$ & $\begin{array}{l}28.8 \\
(29.0)\end{array}$ \\
\hline Per capita after-tax income & $\begin{array}{l}11277 \\
(9046)\end{array}$ & $\begin{array}{c}9572 \\
(6856)\end{array}$ & $\begin{array}{l}12046 \\
(7986)\end{array}$ & $\begin{array}{l}-1.77 \\
(1.67)\end{array}$ & $\begin{array}{c}36.5 \\
(32.1)\end{array}$ & $\begin{array}{c}30.0 \\
(32.6)\end{array}$ \\
\hline $\begin{array}{l}\text { Per capita smoothed after- } \\
\text { tax income }\end{array}$ & $\begin{array}{l}11257 \\
(6906)\end{array}$ & $\begin{array}{c}9782 \\
(4595)\end{array}$ & $\begin{array}{l}12631 \\
(4557)\end{array}$ & $\begin{array}{l}-0.80 \\
(0.70)\end{array}$ & $\begin{array}{c}20.4 \\
(20.2)\end{array}$ & $\begin{array}{c}16.4 \\
(18.9)\end{array}$ \\
\hline $\begin{array}{l}\text { Per capita equivalent after- } \\
\text { tax income }\end{array}$ & $\begin{array}{c}14854 \\
(10483)\end{array}$ & $\begin{array}{l}12204 \\
(7982)\end{array}$ & $\begin{array}{l}14225 \\
(9398)\end{array}$ & $\begin{array}{l}-2.39 \\
(2.00)\end{array}$ & $\begin{array}{c}45.3 \\
(35.9)\end{array}$ & $\begin{array}{c}35.6 \\
(37.3)\end{array}$ \\
\hline $\begin{array}{l}\text { Per capita equivalent } \\
\text { smoothed after-tax income }\end{array}$ & $\begin{array}{l}14383 \\
(6482)\end{array}$ & $\begin{array}{l}12012 \\
(4173)\end{array}$ & $\begin{array}{l}14663 \\
(4530)\end{array}$ & $\begin{array}{l}-1.05 \\
(0.76)\end{array}$ & $\begin{array}{l}24.2 \\
(20.6)\end{array}$ & $\begin{array}{l}19.3 \\
(20.7)\end{array}$ \\
\hline Number of Observations & 155633 & 2685 & 21929 & 155633 & 2685 & 21929 \\
\hline Weighted Number of Obs & 240.2 million & 4.3 million & 4.1 million & 240.2 million & 4.3 million & 4.1 million \\
\hline
\end{tabular}

Notes: The first three columns present mean income pre-reform for individuals classified by family type. The last three columns show the average change in income following the reform. The rows correspond to different measures of after-tax income. Rows 1, 3, and 5 are based on income measures that have not been smoothed using the relationship between after-tax income and consumption in the CEX, while rows 2, 4, and 6 are based on smoothed versions. Rows 1 and 2 use family income, rows 3 and 4 use per capita family income, and rows 5 and 6 use adjusted (for economies of scale and number of adults relative to children) per capita family income. All cells are weighted using the March CPS person weight. Standard deviations are shown in parentheses. 
Table 5. Welfare Analysis

Average change in utility, divided by average marginal value of $\$ 1$

$\theta$

No DI DI Worker DI Elderly

Beneficiary Beneficiary Beneficiary All Individuals

1) Individual Income = per capita family income, not smoothed

$\begin{array}{ccccc}0 & -1.77 & 36.46 & 30.00 & -0.59 \\ 1 & -1.68 & 48.08 & 32.88 & -0.26 \\ 2 & -6.27 & 97.95 & 62.40 & -3.34 \\ 4 & -2.06 \times 10^{9} & 8478.14 & 27726.56 & -1.99 \times 10^{9}\end{array}$

2) Individual Income = per capita family income, smoothed

$\begin{array}{cccc}-0.80 & 20.36 & 16.44 & -0.15 \\ -0.82 & 23.35 & 15.97 & -0.12 \\ -1.13 & 34.54 & 18.00 & -0.20 \\ -372.57 & 221.05 & 55.53 & -355.27\end{array}$

3) Individual Income = adjusted per capita family income, not smoothed

$\begin{array}{ccccc}0 & -2.39 & 45.29 & 35.58 & -0.94 \\ 1 & -2.21 & 63.19 & 43.21 & -0.34 \\ 2 & -7.28 & 131.36 & 91.95 & -3.25 \\ 4 & -1.52 \times 10^{9} & 13408.35 & 73299.58 & -1.47 \times 10^{9}\end{array}$

4) Individual Income = adjusted per capita family income, smoothed

$\begin{array}{lllll}0 & -1.05 & 24.23 & 19.26 & -0.28 \\ 1 & -1.04 & 29.77 & 20.36 & -0.16 \\ 2 & -1.22 & 41.38 & 24.13 & -0.07 \\ 4 & -247.56 & 143.27 & 77.97 & -235.45\end{array}$

Notes: Each panel shows the results of the welfare analysis using a different measure of individual income. The top two panels use unadjusted per capita income $(\mu=\$ 11,260)$, while the bottom two are based on per capita income adjusted for economics of scale and the number of adults and children as described in the text $(\mu=\$ 14,798)$. The measure for after-tax family income that underlies the individual income measures in panels 2 and 4 is smoothed according to the relationship between after-tax income and consumption in the CEX. With each panel, the rows present the results using the indicated relative risk aversion parameter value $(\theta)$. For each level of risk aversion, we show the average change in utility from before to after the reform for separate groups in the first three columns, as well as for all individuals in the last column. The values are converted to dollar equivalents by dividing by the overall average marginal utility of $\$ 1$. 
Table 6. Average Welfare Impact by Education Level

\begin{tabular}{cccccc}
\hline$\theta$ & $\begin{array}{c}\text { All } \\
\text { individuals }\end{array}$ & $\begin{array}{c}\text { Less than } \\
\text { high school }\end{array}$ & $\begin{array}{c}\text { High school } \\
\text { degree }\end{array}$ & $\begin{array}{c}\text { Some } \\
\text { college }\end{array}$ & $\begin{array}{c}\text { College } \\
\text { degree }\end{array}$ \\
\hline 0 & -0.28 & 1.22 & -0.28 & -0.76 & -1.19 \\
1 & -0.16 & 1.27 & -0.23 & -0.71 & -1.18 \\
2 & -0.07 & 1.41 & -0.22 & -0.75 & -1.33 \\
4 & -235.45 & -381.80 & -39.83 & -409.85 & -3.21 \\
\hline
\end{tabular}

Notes: The calculations of the net change in utility are based on smoothed and adjusted per capita after-tax family income (as in panel 4 in the prior table). Positive values indicate that the net welfare impact of a $1 \%$ increase in DI benefit generosity is positive for the subgroup and level of risk aversion $(\theta)$ indicated, while negative values indicate a net welfare loss. The average change in utility for each group is converted to dollar equivalents by dividing by the average marginal value of $\$ 1$ for the group. 
Table 7. Net Welfare Impact with no Factor Loading, by Education Level

\begin{tabular}{cccccc}
\hline$\theta$ & $\begin{array}{c}\text { All } \\
\text { individuals }\end{array}$ & $\begin{array}{c}\text { Less than } \\
\text { high school }\end{array}$ & $\begin{array}{c}\text { Level of Educational Attainment } \\
\text { degree }\end{array}$ & $\begin{array}{c}\text { Some } \\
\text { college }\end{array}$ & $\begin{array}{c}\text { College } \\
\text { degree }\end{array}$ \\
\hline 0 & 0.05 & 1.38 & 0.03 & -0.39 & -0.71 \\
1 & 0.16 & 1.66 & 0.08 & -0.34 & -0.60 \\
2 & 0.29 & 2.17 & 0.14 & -0.32 & -0.57 \\
4 & -173.39 & -512.41 & -35.00 & -277.70 & -1.00 \\
\hline $\begin{array}{c}\text { Implicit } \\
\text { Price }\end{array}$ & 1.00 & 0.22 & 1.02 & 1.96 & 4.62 \\
\hline
\end{tabular}

Notes: The calculations of the net change in utility are based on smoothed and adjusted per capita after-tax family income. Positive values indicate that the net welfare impact of a $1 \%$ increase in DI benefit generosity is positive for the subgroup and level of risk aversion $(\theta)$ indicated, while negative values indicate a net welfare loss. The average change in utility for each group is converted to dollar equivalents by dividing by the average marginal value of $\$ 1$ for the group. Note that the results in this table ignore any costs arising from behavioral responses, and consider only the static or direct costs of the reform. The last row shows implicit prices for an additional $\$ 1$ of disability insurance. The first column simply presents the ratio of overall total costs to the increase in income for current DI recipients, which is equal to one in the absence of behavioral responses. The other columns show the implicit price for families with heads that have the indicated levels of education, constructed in the same way as the last column in Table 3. These values are the average ratio of family costs to expected benefits in the case where there are no behavioral responses. 
Table 8. Net Welfare Impact with Health Insurance, by Education Level

\begin{tabular}{cccccc}
\hline$\theta$ & $\begin{array}{c}\text { All } \\
\text { individuals }\end{array}$ & $\begin{array}{c}\text { Less than } \\
\text { high school }\end{array}$ & $\begin{array}{c}\text { Level of Educational Attainment } \\
\text { degree }\end{array}$ & $\begin{array}{c}\text { Some } \\
\text { college }\end{array}$ & $\begin{array}{c}\text { College } \\
\text { degree }\end{array}$ \\
\hline 0 & -0.36 & 1.18 & -0.34 & -0.85 & -1.32 \\
1 & -0.22 & 1.44 & -0.29 & -0.76 & -1.11 \\
2 & -0.11 & 1.89 & -0.28 & -0.74 & -1.04 \\
4 & 0.38 & 4.34 & -0.13 & -0.70 & -1.33 \\
\hline $\begin{array}{c}\text { Implicit } \\
\text { Price }\end{array}$ & 1.66 & 0.34 & 1.65 & 3.21 & 7.99 \\
\hline
\end{tabular}

Notes: The calculations of the net change in utility are based on smoothed and adjusted per capita after-tax family income. Positive values indicate that the net welfare impact of a $1 \%$ increase in DI benefit generosity is positive for the subgroup and level of risk aversion $(\theta)$ indicated, while negative values indicate a net welfare loss. The average change in utility for each group is converted to dollar equivalents by dividing by the average marginal value of $\$ 1$ for the group. Note that the results in this table incorporate health insurance in two easy. First, the total costs of the reform include any costs associated with shifts to public insurance among marginal applicants (\$30.5 million in new Medicare costs and $\$ 14.8$ million in new Medicaid costs). Second, family income is randomly reduced to account for differences in medical outlays as described in Appendix D. The last row shows implicit prices for an additional $\$ 1$ of disability insurance. The first column simply presents the ratio of overall total costs to the increase in income for current DI recipients. The other columns show the implicit price for families with heads that have the indicated levels of education, constructed in the same way as the last column in Table 3 . These values are the average ratio of family costs to expected benefits when health insurance is incorporated in the analysis. 